\title{
TASAS DE INTERÉS Y DESEMPEÑO ECONÓMICO: EL CRÉDITO COMERCIAL EN SANTAFÉ DE BOGOTÁ, 1760-1810
}

\section{INTEREST RATES AND ECONOMIC PERFORMANCE: TRADE CREDIT IN SANTAFE DE BOGOTA, 1760-1810}

\author{
James Vladimir Torres Moreno \\ Universidad Nacional de Colombia, Bogotá, Colombia <jvtorresm@unal.edu.co>
}

\begin{abstract}
Resumen. Este artículo analiza el crédito otorgado por los comerciantes de Santafé de Bogotá entre 1760 y 1809. Para ello, se han construido series de tasas de interés y préstamos en moneda y efectos de Castilla que permiten analizar su comportamiento a largo plazo. Se encontró que los mercaderes capitalinos pusieron a disposición de la economía colonial cantidades crecientes de fondos prestables. Por su parte, la evolución de las tasas de interés indica una reducción de los tipos máximos a fines de siglo y una cierta elasticidad de la oferta de crédito frente a dicha reducción. Además, se sostiene que el mercado monetario disminuyó significativamente sus costos de transacción y aumentó su tasa de rotación de capital. Así, aumentaron los incentivos para que los comerciantes aumentaran sus créditos en moneda, lo que pudo haber impulsado el crecimiento económico.
\end{abstract}

Palabras clave: historia económica; crédito; tasa de interés; comerciantes; Santafé de Bogotá.

Abstract. This article analyzes the credit given by merchants in Santafe de Bogota between 1760 and 1809. This required the preparation of interest rates and loans in both currency and Castilian effects, which permitted a long-term behavior analysis. It was found that the capital's merchants made increasing amounts of loanable funds available for the colonial economy. Meanwhile, towards the end of the century, the evolution of interest rates points towards a reduction in the maximum rates, as well as a consequential relaxation of the credit supply. Furthermore it became apparent that the money market significantly reduced its transaction costs while swelling its capital turnover, thus creating an increased incentive for merchants to augment their currency loans, which in turn may have stimulated economic growth.

Key words: economic history; credit; interest rates; merchants; Santafe de Bogota.

Fecha de recepción: agosto de 2013. Fecha de aceptación: noviembre de 2013.

* El autor agradece los comentarios del Grupo de Investigación en Historia Económica de la Universidad Nacional de Colombia, sede Bogotá. Todos los errores y omisiones son enteramente del autor. Este artículo es parte de la investigación Circulación y Producción de Oro en Colombia

Am. Lat. Hist. Econ., año 21, núm. 3, septiembre-diciembre, 2014, pp. 9-45 


\section{INTRODUCCIÓN}

$\mathrm{L}$ as recientes investigaciones en historia económica de Kalmanovitz (2006 y 2008) y de Meisel (2011) han hecho énfasis en el comportamiento a largo plazo de la economía neogranadina. Desde un punto de vista agregado, la economía del virreinato habría entrado en un fuerte crecimiento nominal a fines del siglo XVIII, que diverge del desempeño económico en el siglo siguiente. Sin embargo, decir que hubo crecimiento no es suficiente. En efecto, es necesario analizar las series en términos reales y complementar las investigaciones del comportamiento del sector real con un análisis de los precios relativos, la oferta monetaria y el sistema de crédito. Sólo así se puede tener una imagen más completa del significado y las causas del crecimiento de la economía colonial.

En ese sentido, en el presente artículo estudiamos el crédito otorgado por los comerciantes de Santafé de Bogotá examinando el comportamiento del mercado monetario y el mercado de efectos de Castilla durante la segunda mitad del siglo XVIII. ${ }^{1}$ Para ello, hemos construido series de tasas de interés y de préstamos en moneda y efectos de Castilla otorgados por comerciantes residentes y sedentarios en las notarías de Santafé entre 1760 y 1810. Los comerciantes sedentarios son aquellos que tienen su centro de operaciones en la ciudad de Santafé y los residentes son aquellos que están temporalmente en la ciudad. Por otra parte, es importante recordar que en Santafé no había una distinción marcada entre mercaderes y comerciantes, de hecho, el Plan de una compañía patriótica de comercio (1801) señala que "se echa de menos el contraste entre los que aquí se pueden llamar comerciantes, y los que comúnmente son conocidos con el nombre de mercaderes" (p. 107).

Esta construcción de series se trata de un ejercicio interesante por varias razones. En primer lugar, permite examinar cómo reaccionaron los comerciantes, quizá el grupo con mayor liquidez de la sociedad colonial, al crecimiento económico y a la formación de un incipiente mercado de capitales. En segundo lugar, las tasas de interés constituyen una de las variables macroeconómicas fundamentales por su estrecha relación con la oferta monetaria, la velocidad de circulación y su importancia en la disyuntiva entre consumo y ahorro en el corto y largo plazos (véase Torres, 2012). En tercer lugar, el crédito comercial constituyó una importante alternativa a un crédito eclesiástico caracterizado por una oferta inelástica de

y Brasil, coordinada por Heraclio Bonilla y Ángelo Alves Carrara y financiada por la Dirección de Investigaciones sede Bogotá de la Universidad Nacional de Colombia y por la Universidade Juiz da Fora, Brasil.

${ }^{1}$ Aquí nos referiremos a este tipo de crédito como crédito comercial o mercantil. Es importante que el lector no confunda el primer término con el crédito comercial actual. 
fondos prestables. Finalmente, y no menos importante, ambos mercados (monetario y de bienes importados) constituyen un importante elemento en los costos explícitos de la actividad comercial. En otras palabras, desde el punto de vista del comerciante, el mercado monetario constituye un costo de oportunidad de sus actividades comerciales habituales.

Según Martínez y Valle (1998), y Pietschmann (1996), la historiografía colonial latinoamericana se ha concentrado en lo que genéricamente se ha denominado crédito eclesiástico. Un tema recurrente en dichos estudios ha sido el debate como lo exponen Bauer (1983) y Romano (1997, 2004) en torno al impacto positivo o negativo de los distintos instrumentos de crédito que la Iglesia puso a disposición de la economía colonial. No es nuestra intención abordar con detalle un debate que, por lo demás, requiere mayores investigaciones. Lo que sí nos interesa resaltar es la notable ausencia de estudios específicos sobre el crédito comercial y su relación con el crédito eclesiástico. Aunque Pérez (1988) ha examinado el funcionamiento de algunos instrumentos mercantiles como los vales y las libranzas, no se ha emprendido la construcción de series que permitan examinar el comportamiento del crédito comercial y su relación con la economía colonial. De hecho, como señalan Martínez y Valle (1998), se han examinado los préstamos de los comerciantes en función de carreras mercantiles particulares pero no se ha abordado el fenómeno como se ha hecho con el crédito eclesiástico.

En el caso de Nueva Granada, Germán Colmenares (1997a) dejó una apreciación demasiado estática de la economía colonial donde las instituciones religiosas - con su baja rotación del capital, sus privilegios institucionales y sus rígidas tasas de interés- dominaron la oferta de crédito. En otras palabras, a una economía de ritmo lento se ajustaba bien un sistema de crédito de este tipo. Sin embargo, no resulta convincente que el crédito eclesiástico, por sí sólo, hubiese podido proporcionar los capitales necesarios para sostener un importante crecimiento nominal del PIB. De hecho, el mismo Colmenares (1997a) se apresuró a señalar que, a mediados del siglo XVIII "el volumen de las obligaciones comerciales sustituye el viejo mecanismo de los censos, que privilegiaban la agricultura" y, de manera más clara, que "mientras el volumen de los censos disminuía a ojos vista durante el resto del siglo, las obligaciones simples de los comerciantes iban en aumento" (p. 99).

Los estudios de Castro y Montoya (2009), Ferreira (1999) y Toquica (2008) han abordado el crédito eclesiástico a escala regional y su desarrollo en conventos particulares. Quizá el texto de Renée Soulodre-La France (2004) es el más importante de estos estudios porque analiza con detalle los préstamos a través de los escribanos y, principalmente, porque ha llamado la atención sobre el crédito particular y su impacto en la oferta 
local de crédito. Los estudios de Daza (2009), McFarlane (1983) y Twinam (1985) sobre comerciantes también han abordado el problema pero, como sucede en la historiografía latinoamericana, se hace en función de la actividad comercial por sí misma y no en su relación con la economía que la rodea. Así, no es arriesgado decir que el crédito comercial ha permanecido ausente de la agenda de los investigadores de la época colonial; la excepción para el siglo XIX se encuentra en Meisel y López (1990).

Este vacío no se trata, por cierto, de una traducción de la ausencia de investigaciones empíricas concretas. Por el contrario, se debe a la hipótesis -aún por demostrarse- de que en realidad el crédito por los comerciantes fue marginal, que su capacidad de dinamizar la economía colonial fue reducida y, como corolario, que no se puede hablar de un incipiente mercado de capitales (Romano, 1997, 2004), esto último agravado por la política religiosa de control de las tasas de interés y por la restricción de la entrada y salida de los agentes a este tipo de transacciones. Esta hipótesis, sin embargo, ha sido puesta en duda. En un estudio de las finanzas del virreinato de Nueva España y su influjo en la estructura del imperio español, Carlos Marichal $(1997,1998)$ afirmó que "hacia fines de la colonia efectivamente existía un sistema crediticio y un mercado de capitales complejo y relativamente exigente". Además, es importante puntualizar que el hecho de que los precios de ese mercado tuvieran un tipo máximo fijado por las autoridades no significa que no exista ese mercado. La coordinación de ese mercado de capitales se puede seguir en la época moderna a través de los comerciantes, quienes son los que tenían mayor capacidad de ahorro (Bordo y Cortés, 2001). Así, buscamos aportar a la discusión analizando con relativo detalle el mercado de la capital neogranadina, ciudad que entró en una importante expansión por el crecimiento de su población y por sus particulares funciones en la distribución de mercancías e importancia política.

En este artículo abordamos la evolución de las tasas de interés de diversos tipos de crédito y las características de estas tasas en el marco de la economía colonial. También analizamos los montos agregados de créditos y su elasticidad a la tasa de interés y estudiamos otras variables que intervienen en la oferta de crédito como plazos, riesgos y tasas de retorno.

\section{LAS TASAS DE INTERÉS}

En el periodo colonial existieron varios tipos de interés según el tipo de institución que otorgara o recibiera el crédito (Reyes, 2000). Estas tasas, además, no fluctuaron al unísono como lo suelen hacer en la economía moderna. Así, los instrumentos financieros eran los siguientes: las escritu- 
ras de deuda del virreinato, los préstamos eclesiásticos, el préstamo particular, el préstamo comercial y los préstamos de las cajas de comunidad. Sobre el primer tipo de interés tenemos información confiable para la Caja de Santafé. Según el "Estado caudales cargados contras estas reales cajas [de Santafé] [sic]", ${ }^{2}$ que relaciona la deuda que tenían las cajas matrices para 1769, la evolución de la tasa de interés era la siguiente: los juros (bonos de deuda) del siglo XVII tenían una tasa de interés de 5\%. Durante el reinado de Felipe V (1700-1746) y Fernando VI (1746-1759), ${ }^{3}$ la tasa de interés subió a 6\%. Para la fecha del "Estado" la tasa de interés era de nuevo de $5 \%$ y sufrió una reducción definitiva en 1781 a 4 por ciento. ${ }^{4}$

El préstamo eclesiástico se mantuvo a lo largo del siglo XVIII en 5\% aunque se alteró en algunos años. En 1756, por ejemplo, la Audiencia de Quito disminuyó la tasa de 5 a 3\%. Según Colmenares (1997b) esta reducción afectó diversos territorios que pertenecían al Nuevo Reino, como Popayán. Esto contrasta con la experiencia de Nueva España, donde a fines del siglo se redujo a 4.5\% (Wobeser, 1998); Perú, donde se bajó en algunos años a 3\% (Quiroz, 1994) y en la península, donde la tasa se mantuvo en 3\% antes de la emisión de los vales reales (Romano, 2004). Sobre los créditos de las cajas de comunidad es poco lo que sabemos puesto que los trabajos existentes no han desarrollado un estudio sistemático del comportamiento económico de los pueblos de indios más allá de las descripciones tradicionales. Si nos entregamos a la información disponible, la tasa de interés de las cajas de comunidad también se mantuvo en 5 por ciento. ${ }^{5}$

Los préstamos de particulares y de los comerciantes, en cambio, sufrieron modificaciones importantes. La Real Audiencia era la encargada de asignar la tasa techo para ambos tipos de crédito. ${ }^{6}$ Sin embargo, es claro que la tasa máxima era una variable exógena, y factores como el tiempo de retorno y el riesgo no afectaban de manera directa el precio del capital sino la oferta de fondos prestables. Aun cuando Redd y Bekar (2003) ofrecen una interesante explicación de la evolución de las tasas de interés desde la teoría neoclásica, infortunadamente ignoramos las discusiones y

2 (1769). Real Hacienda (Estado caudales cargados contras estas reales cajas, anexo 1, t. 8, fs. 526-524). Archivo General de la Nación. Bogotá, Colombia.

${ }^{3}$ La contabilidad de la deuda de la Real Hacienda se llevaba por reinados.

${ }^{4}$ (1781). Real Hacienda (anexo 1, t. 8, fs. 710-711). Archivo General de la Nación. Bogotá, Colombia.

${ }^{5}$ (1794). Notaría Segunda (Préstamo de 10000 pesos, t. 187, f. 209). Archivo General de la Nación. Bogotá, Colombia; (1804). Notaría Segunda (Préstamos por 35879 pesos, t. 207, fs. 180205v). Archivo General de la Nación, Bogotá, Colombia. Ambas cifras muestran la magnitud del fenómeno.

${ }^{6} \mathrm{El}$ crédito de particulares requiere otro trabajo. Es de suponer que, puesto que en Santafé residía un tipo de burocracia con alta liquidez, los préstamos también debieron ser de cierta magnitud. Véase, por ejemplo, (1756). Fondo Camilo Torres (carpeta 50, fs. 1-60). Archivo Histórico Javeriano. Bogotá, Colombia. 
razones que llevaron a esta institución a reducir las tasas de interés. De hecho, en el texto clásico de Ots (1950) no hay información sobre este tipo de funciones de la Real Audiencia. Se requieren trabajos que analicen la perspectiva que tenían las autoridades neogranadinas sobre la usura.

Para el crédito comercial hemos construido la evolución de los tipos de interés siguiendo la expresión "réditos a estilo y uso del comercio", que era la expresión usada para este tipo de interés. Dicha serie se construyó con base en todos los préstamos en dinero y efectos de Castilla hechos por comerciantes de la capital en las notarías segunda y tercera entre 1760 y $1810 .^{7}$ En un trabajo anterior, Torres (2011) logró localizar y estudiar esa comunidad de comercio y estableció sus integrantes, con lo cual identificamos a los individuos que, siendo comerciantes, prestaban dinero pero no se presentaban como individuo del comercio o como mercader de esta ciudad. Se trata de una base de datos que abarca 1404 transacciones (797 de efectos de Castilla y 607 en moneda). Naturalmente, debemos tener cierto cuidado en su lectura. Las obligaciones ante los escribanos no representan el total de los préstamos del sector comercial, pues se usaban también los libros de caja, las libranzas y los vales (Pérez, 1988; Bohórquez y Palacio, 2008). Aquí asumiremos que los datos de las notarías son un buen reflejo de la tendencia. Finalmente, es importante anotar que los comerciantes recibían dinero de particulares -especialmente de viudas y funcionariospara ponerlos a premio, ${ }^{8}$ lo que indica, por otra parte, la función de intermediarios financieros que habían desarrollado los comerciantes. En el Plan de una compañía patriótica de comercio (1801) se hace énfasis en que "ahora se ve que muchos sujetos eligen a un mercader para el adelantamiento de sus intereses" (p. 108). Esta forma de canalizar dineros mediante los comerciantes es una experiencia que se puede encontrar en otras economías coloniales. Sobre Nueva España, véase Brading (1995), y sobre Buenos Aires, Socolow (1991).

${ }^{7}$ Se han revisado todos los escribanos de la capital existentes en el Archivo General de la Nación agrupados en las notarías segunda y tercera entre las fechas descritas, exceptuando las escribanías de Diezmos y de Real Hacienda. La notaría primera no se incluyó en la muestra, pues presenta un notable vacío entre 1790 y 1805 , aproximadamente. De la notaría segunda se revisaron los escribanos entre los tomos 122 al 215 y de la notaría tercera aquellos comprendidos entre los tomos 208 y 349 .

${ }^{8}$ Ejemplos de entrega de dineros a comerciantes de la capital y que informan sobre los mecanismos de estos tratos se pueden consultar en: (1763 y 1800). Notaría Segunda (t. 127, fs. 403$404 v$ y t. 198, fs. 338-338v). Archivo General de la Nación. Bogotá, Colombia. 
Además, hemos realizado dos series adicionales, una para Medellín ${ }^{9}$ y otra para Popayán, ${ }^{10}$ que nos permiten tener una imagen comparada del fenómeno. En el caso antioqueño para el periodo 1750-1810 los resultados arrojan una línea horizontal de $5 \%$ con algunos años, muy puntuales, acercándose a $6 \%$. Igualmente, en muy pocas ocasiones se hace referencia explícita a una tasa de interés "a estilo de comercio", lo que indica que los préstamos se hicieron con base en la tasa de los créditos eclesiásticos. Para Popayán, la serie presenta tasas de interés de 10\% entre 1750 y 1764 para bajar en ese año a $8 \%$ y fluctuar hasta 1773 , cuando la tasa de interés máxima se reduce a $6 \%$. En el caso de Santafé, tenemos una disminución consistente de los tipos de interés. Tanto el crédito comercial como el crédito de particulares estuvo en 10\% hasta 1763, cuando la Real Audiencia obligó a ajustarlos a 5\% para obedecer una Real Pragmática y mantenerse allí hasta 1772, cuando los comerciantes lograron subir un punto porcentual la tasa techo. Los particulares no pudieron prestar más allá de $5 \%$. Esta caída es ciertamente notable. En estas condiciones, es claro que la tasa de interés sufrió una baja y con ella cayó el costo de oportunidad de tener saldos monetarios en caja. Es evidente la mayor reducción de las tasas en la capital virreinal frente a otras ciudades del reino.

Desde un punto de vista comparado, una disminución de las tasas de interés por la misma época también se presentó en otras economías como Chile (Cavieres, 1996) y el interior argentino (Socolow, 1991; Mata, 1996). No así en Nueva España, donde las tasas se mantuvieron sobre 12\%, aunque venían disminuyendo años atrás (Romano, 2004). Según Valle (2012), aún a fines de siglo algunos comerciantes novohispanos prestaban a tasas anuales por encima de $25 \%$ en las notarías, de hecho interpreta esta reducción en la tasa como una consecuencia de la apertura del comercio libre que afectó a los antiguos flotistas y los obligó, aunque parcialmente, a colocar sus capitales a rédito. Sin embargo, por lo menos para el caso de Nueva Granada, la reducción venía de años atrás y estuvo condicionada por variables exógenas. Naturalmente, los comerciantes tenían diversas formas de evadir legalmente la restricción. Sin duda, estaban a disposición estrategias que podríamos denominar clásicas: inflar el valor del principal y alterar los tiempos de cancelación (Bell, Brooks y Moore, 2008).

Del mismo modo, es importante anotar que la tasa de interés recaía sobre la venta a crédito de efectos cuando se vencían los plazos estipula-

${ }^{9}$ (1750-1810). Escribanos de Medellín. Archivo Histórico de Antioquia. Medellín, Colombia. Se revisaron todos los escribanos comprendidos en las anteriores fechas (el archivo no ha clasificado por tomos o legajos los protocolos). También examinamos todas las deudas particulares, pues no tenemos información de los comerciantes y sus actividades financieras.

${ }^{10}$ (1750-1810). Escribanos. Archivo Central del Cauca. Popayán, Colombia. Aquí seguimos las escrituras para las cuales se hace explícito el rédito a estilo de comercio. Muestra de años pares. 
dos, en ese momento, para usar una de las expresiones de la época: "se convierten los efectos en dinero potable". ${ }^{11}$ Desde el mercado de efectos, también es importante anotar que sólo 8.5\% de las transacciones se pactó con pago en otros efectos en una especie de trueque. ${ }^{12}$

Finalmente, y muy importante, nos hemos referido a la tasa de interés máxima en términos nominales, aunque no hemos dicho nada sobre la fluctuación de la tasa de mercado y sus montos ajustados a la inflación. Así, hemos construido una serie de tasas de interés promedio para observar su fluctuación a pesar de la existencia de una tasa máxima. Al someter la desviación estándar (DS) de esos promedios a la prueba $t$ de Student, se tiene que, en términos nominales, en realidad la variación no fue importante y se mantuvo siempre entre 5 y $6 \%$, excepto cuando la DS es cero debido a que todos hicieron sus préstamos a 5\% (para 1793 y 1796). ${ }^{13}$ Sin embargo, el panorama es distinto cuando pasamos a analizar la tasa en términos reales. Como se sabe, la historia de los precios es quizá el área de la historia económica menos explorada por los historiadores colombianos. Un trabajo reciente (Torres, 2012) ha construido un nuevo índice de precios que abarca el periodo $1791-1808 .{ }^{14}$ Según los resultados de dicho índice, la inflación promedio anual se ubicó en 1.7\%, aunque hubo años en que el crecimiento de los precios fue mayor, en especial en los últimos años de la dominación colonial.

La gráfica 1 señala una reducción de la tasa de interés a fines del periodo al deflactarla por el índice de precios de la capital virreinal. La tasa máxima real se benefició de algunos años de deflación, aunque llegó a estar por debajo de 5\%; la tasa de mercado, por su parte, llegó a aproximarse a $4 \%$, aunque a fines del periodo colonial el incremento parcial en la tasa nominal amortiguó en parte la inflación. Estos guarismos nos hablan de una coyuntura favorable para la demanda de crédito. En efecto, esta reducción incentivó el grado de sustitución del crédito comercial frente al crédito eclesiástico, lo que en un panorama de crecimiento de la producción pudo haber incentivado la inversión y el consumo. Del lado de la oferta, sin embargo, es necesario calibrar la reacción de los comerciantes:

\footnotetext{
${ }^{12}$ La transacción más elevada con este tipo de pago fue hecha en 1802, donde se pactaba la venta de 20160 pesos en efectos de Castilla a pagar en lienzo y mantas del Socorro, especificando los precios de estos últimos. (1802). Notaría Segunda (tt. 204, 435). Archivo General de la Nación. Bogotá, Colombia.

${ }^{13}$ La prueba $t$ de Student es una prueba de hipótesis que nos permite inferir si una media es diferente frente a otra a partir de sus valores y su desviación estándar. A lo largo del texto hemos aplicado la prueba, pues hemos utilizado in extensu promedios que en apariencia son diferentes.

${ }^{14}$ En dicho trabajo se hace una defensa apropiada a metodologías estadísticas y económicas que son injustamente tratadas de anacrónicas.
}

${ }^{11}$ (1780). Notaría Segunda (t. 161, fs. 141-141v.). Archivo General de la Nación. Bogotá, Colombia. 


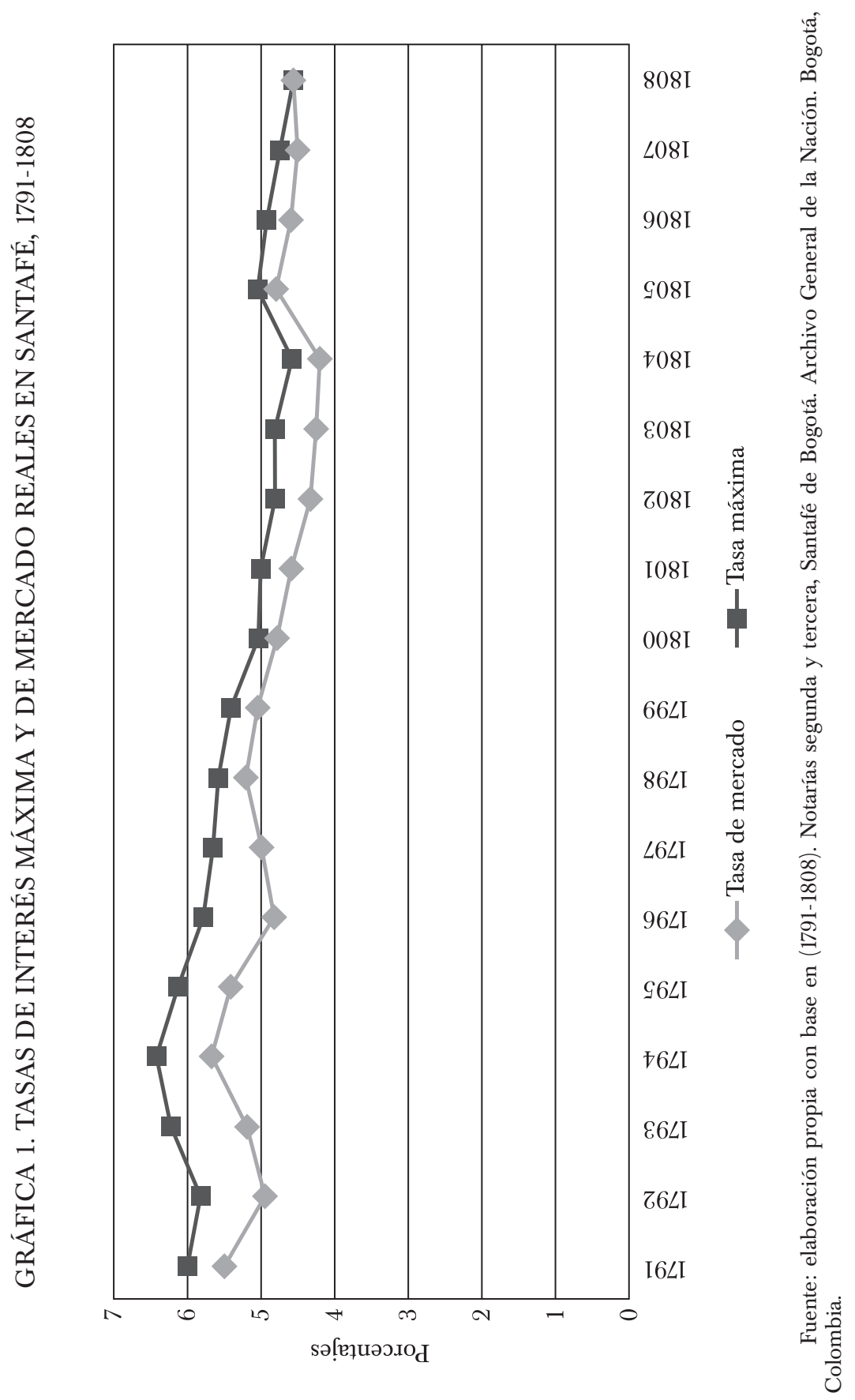


¿la oferta de crédito es elástica a la tasa de interés? Analizaremos esta pregunta en la siguiente sección.

\section{LA ELASTICIDAD PRECIO OFERTA DEL CAPITAL}

Los comerciantes fueron quizá el sector que gozó de mayor liquidez en la economía colonial, la razón fue su importante movimiento entre la economía natural y la economía monetaria y, a su vez, por su constante interés en minimizar sus gastos en América y maximizar sus excedentes a Europa. De esta manera, los comerciantes habrían sido los "agentes de la desmonetización" de la economía colonial (Gelman, 1987). Nos parece, sin embargo, que este encuadre es demasiado simple. En efecto, para llegar a la conclusión de que los comerciantes actuaban de manera mecánica como exportadores insaciables de moneda, es necesario evaluar los incentivos y restricciones que ofrecía la economía doméstica a las actividades comerciales.

Iniciemos con el comportamiento en el mercado de efectos de Castilla (véase gráfica 2). Entre 1760 y 1809 pasaron por las notarías de Santafé un total de 3036271 pesos plata en efectos de Castilla vendidos a crédito. Se trata de una fracción ciertamente menor si la comparamos con la evolución de las alcabalas, que es el indicador más sólido de ventas totales de este bien en el mercado; el recaudo constituía $2 \%$ del valor de avalúo de las mercancías (Muñoz, 2010). Aunque en términos absolutos la diferencia es abismal, pues las alcabalas informan de transacciones totales hasta de 1000000 de pesos anuales, la tendencia es similar. Además, insistamos en que las notarías nos proporcionan una serie de variables ausentes en las fuentes alcabalatorias como la tasa de interés y los plazos del crédito.

Volviendo a los números, es clara la volatilidad de este mercado debido a los grandes rezagos que causaron las guerras internacionales en las que España participó. Si siguiéramos la tendencia lineal tendríamos un crecimiento importante en ese mercado. Sin embargo, este no es acelerado si seguimos la media móvil de dos años, situación que se corrobora con el comportamiento de las alcabalas. Asimismo, es necesario tener en cuenta que quizá esa estabilidad en el valor global de las importaciones se deba a una reducción de los precios de estos.

Sobre el influjo de la tasa de interés en estas ventas a crédito, se puede afirmar que los efectos de Castilla no son un bien elástico a la tasa de interés. La reducción de esta en 1763 no causó un auge perceptible en los montos transados medidos por las transacciones notariales y por la alcabala. De hecho, a los grandes picos de fines de la década de los ochenta y fines de los noventa siguen valles comparables a los de principios de 


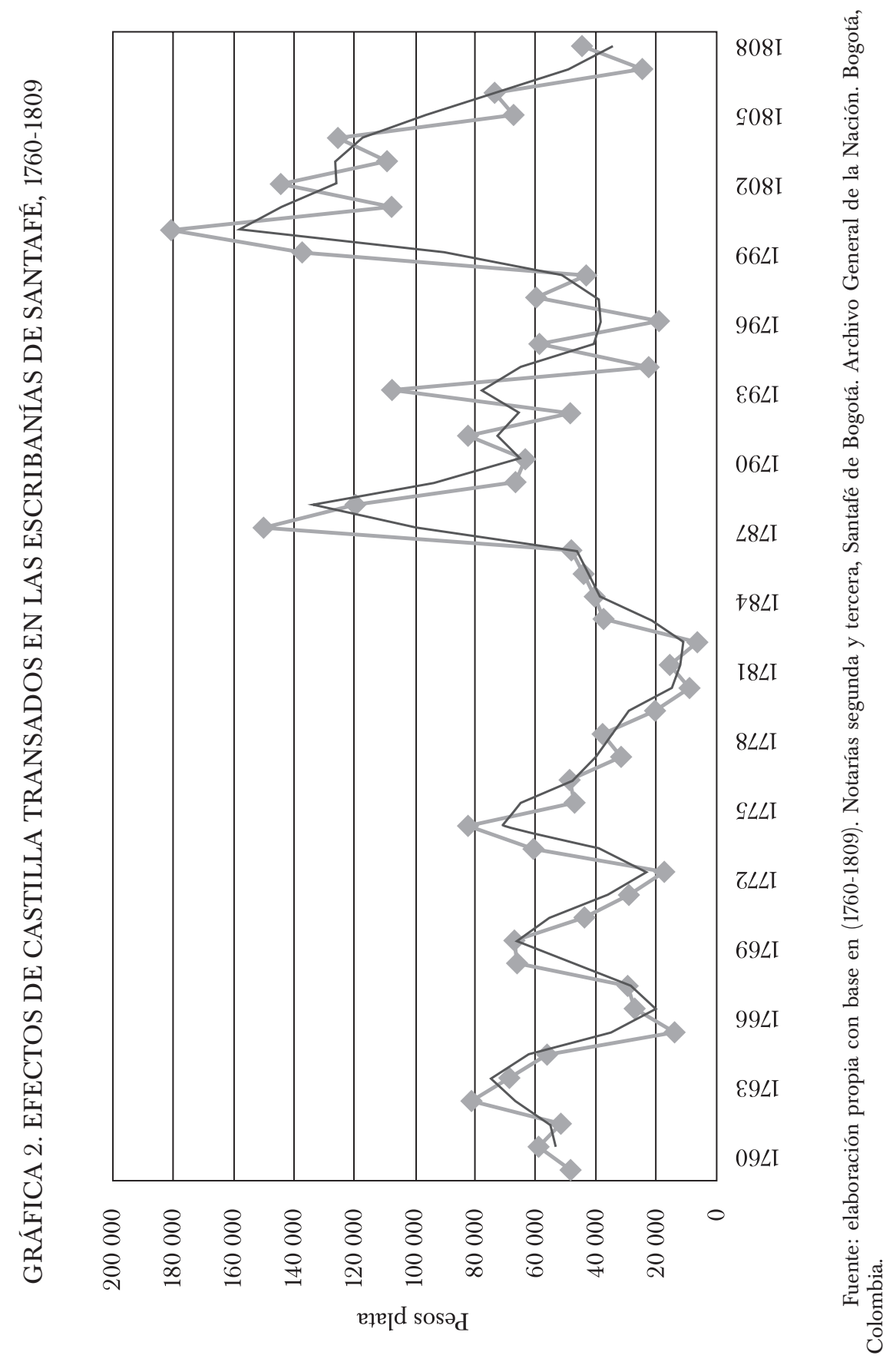


1760. Igualmente, es probable que los picos en esos años hayan saturado la demanda de aquellas provincias que se abastecían de estos efectos en la capital.

Procedamos a analizar los montos agregados de los préstamos en moneda concedidos por los comerciantes capitalinos (véase gráfica 3). Para el periodo 1760-1809, los mercaderes pusieron a disposición de la economía, vía notaría, 1912436 pesos, de los cuales 1025192 pesos fueron en plata y 887244 en oro. La primera constatación del movimiento de esos préstamos es el aumento acelerado del crédito desde 1780 hasta $1805 .^{15}$ La segunda constatación también es evidente: una importante presencia de doblones en el mercado doméstico. Para observar este fenómeno de manera mucho más precisa, véase la gráfica 4, donde presentamos los préstamos desagregados por metales. El oro, sin duda, presentó un notable crecimiento a fines del periodo mencionado, interrumpido por un importante valle entre 1792 y 1797 , tiempo en que tal vez los comerciantes esperaron el movimiento del comercio internacional (véase McFarlane, 1997). Frente a la plata, debemos señalar que allí hemos agrupado la macuquina o corriente y la plata fuerte. Los préstamos en la segunda fueron muy reducidos (21 585 pesos), lo que indica la mayor importancia en la circulación de la primera. Su comportamiento también es creciente y menos volátil que el oro.

La reducción de la tasa de interés en 1763 indujo a una desaparición casi total en los préstamos de doblones, aunque la tasa de mercado venía bajando con una importante volatilidad (medida por la DS). Tal vez la tasa de interés de equilibrio rondaba en $8 \%$. En todo caso, únicamente se prestaban monedas de plata en esos años. Sólo hasta 1775, luego del aumento en un punto porcentual de la tasa de interés, se reactiva el préstamo de numerario de metal amarillo. A partir de esa fecha, los préstamos entraron en un constante crecimiento, lo que indica que parte de los comerciantes estaban dispuestos a prestar por debajo de esa tasa, hecho que se confirma por la tasa de mercado promedio. ${ }^{16}$ La situación se refuerza en la década de los noventa. En ese momento, como hemos señalado, la DS es cero para dos años (1793 y 1796), lo que señala que todos prestaron a 5\%, un punto porcentual menos que la tasa de interés máxima. ${ }^{17}$

${ }^{15}$ Este crecimiento acelerado se constata, por lo demás, con las pendientes de regresión lineal por décadas.

${ }^{16}$ Sin embargo, insistamos en que el comerciante podía, ilegalmente, prestar a tasas superiores. En un libro de cuentas de una compañía comercial de Santafé hacia 1796 se registran préstamos a 5, 6, y uno de 8\%. (1796) Real Hacienda Cuentas (anexo 3, 2896-c.). Archivo General de la Nación. Bogotá, Colombia.

${ }^{17}$ De hecho, cuando se prestaba a la tasa de $5 \%$ se solía usar la expresión "que son los premios más moderados del comercio”. (1783). Notaría Segunda (t. 166, f. 138v). Archivo General de la Nación. Bogotá, Colombia. 


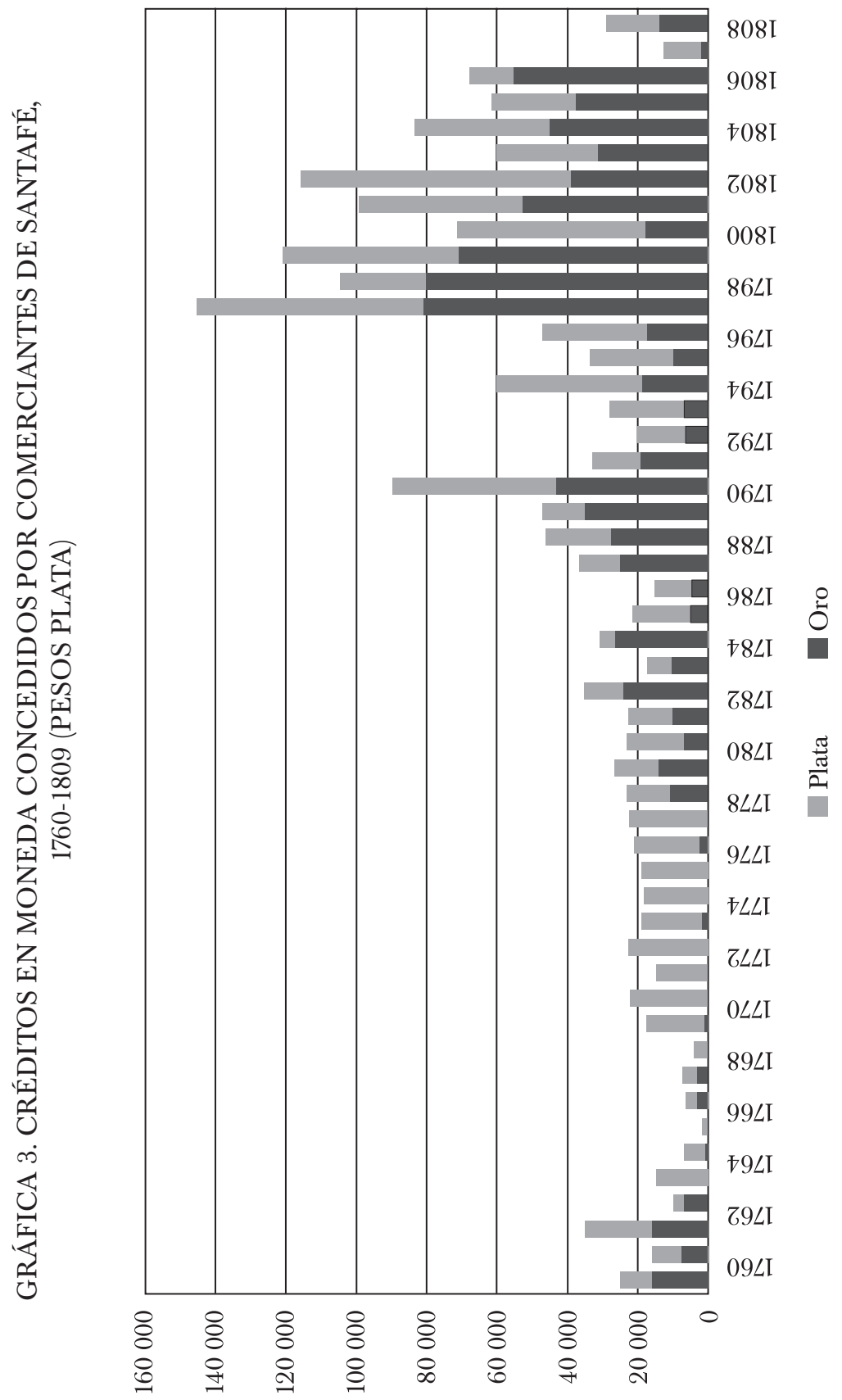

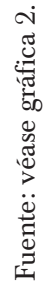




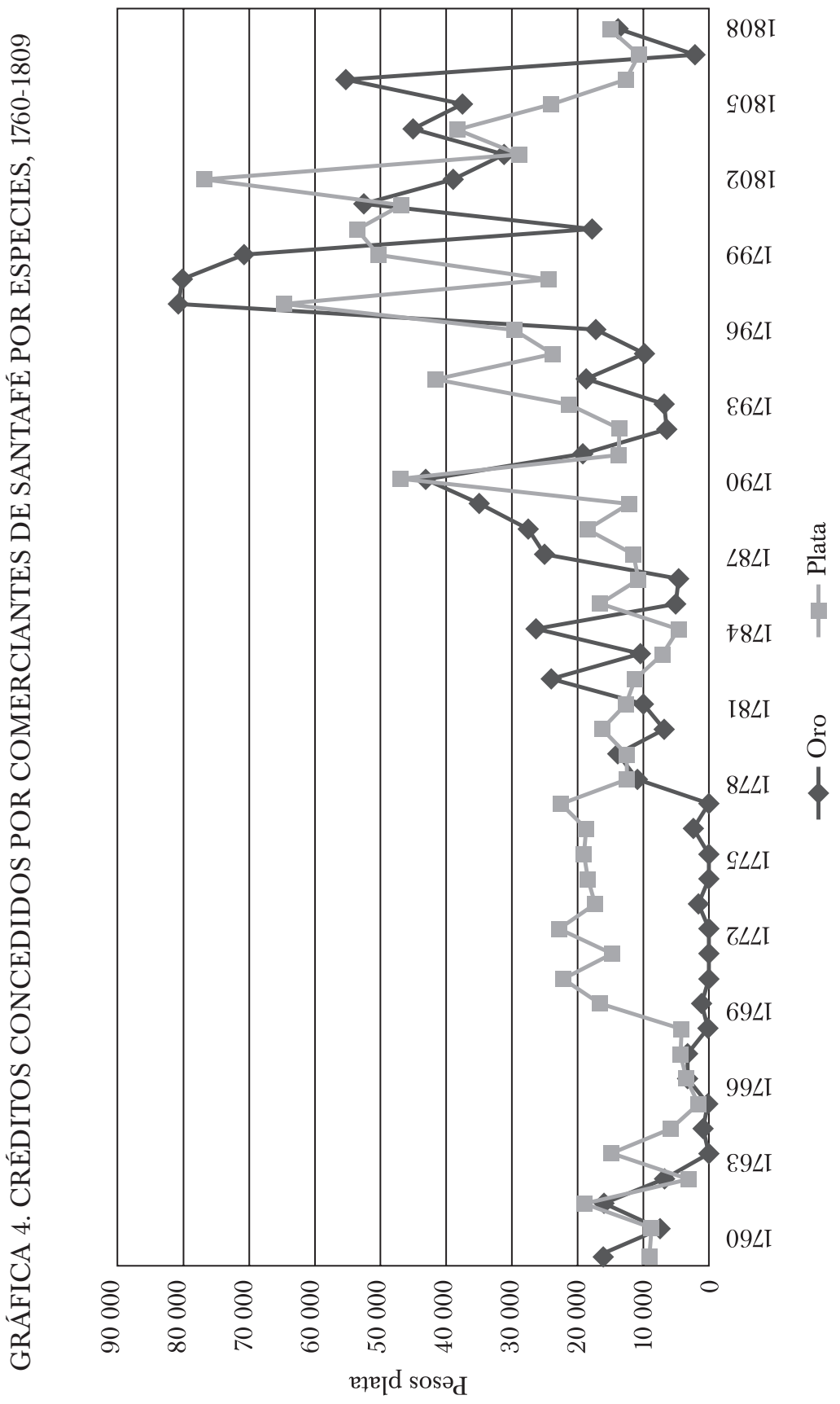

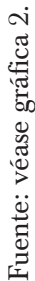


Ahora bien, es necesario poner a dialogar ambos mercados para estudiar una posible relación de asociación. En primer lugar, es notoria la similitud entre la tendencia polinómica de los efectos de Castilla tanto con el agregado monetario como con la plata y el oro. Desde la media móvil se observa un rezago débil a fines de siglo entre ambas curvas. Sin embargo, los coeficientes de correlación Pearson durante todo el periodo son bastante tenues (0.39 oro, 0.50 plata y 0.49 agregado). De hecho, al aplicar el mismo coeficiente por décadas, las correlaciones tienden a disminuir (en la década de los noventa fueron 0.23 para oro y 0.08 para plata). Asimismo, podemos inferir tres consideraciones: $a$ ) los préstamos concedidos por comerciantes no fueron absorbidos totalmente por sus colegas del sector importador, b) al no estar vinculados de manera directa, ambos sectores actuaron como alternativas recíprocas para los comerciantes, y $c$ la reducción en las tasas de interés pudo haber hecho más atractivo el mercado de Santafé frente a otros, aunque probar esto último requiere de análisis regionales detallados.

Para finalizar esta sección, nos parece importante realizar una primera aproximación al impacto de los créditos monetarios para la economía colonial. En la segunda mitad del siglo XVIII es claro que los comerciantes comenzaron a generar una serie de excedentes que pronto convirtieron en fondos prestables. El monto máximo alcanzado, vía notarías, fue de unos 120000 pesos anuales hacia 1800. Si lo contrastamos en términos agregados, esos fondos significaron menos de 1\% del PIB (Kalmanovitz, 2006; Meisel, 2011). Naturalmente, y debemos insistir en ello, esos dineros fueron mucho más elevados pues ignoramos los caudales que escapan a las notarías. Ahora bien, explicar ese crecimiento de los fondos prestables a partir de la tasa de interés es sólo una parte del ejercicio. En efecto, las restricciones religiosas a la tasa de interés son sólo un aspecto de las limitaciones a la consolidación de un mercado de capitales en las economías preindustriales. Existieron, en efecto, otros obstáculos como el nivel de riesgo, los altos costos de transacción e información y la baja tasa de rotación de esos capitales. A estas variables dedicaremos la siguiente sección.

\section{OTRAS VARIABLES}

Iniciemos una vez más por el mercado de efectos de Castilla. Hemos dividido el mercado en tres tipos de transacciones: pequeñas, que comprenden el intervalo de transacciones de 0 a 999 pesos; medianas, que abarcan aquellas entre 1000 y 9999 pesos; grandes, que corresponden a todas aquellas mayores a 10000 pesos. Aunque se trata de una división artificial, nos permitirá observar el comportamiento segmentado del mercado y su grado 
de concentración. Además, nos hemos guiado por los montos establecidos por el consulado de Cartagena para la clasificación de sus miembros (Múnera, 1998).

$\mathrm{Al}$ analizar el número de transacciones (véase gráfica 5) observamos que este indicador se mantuvo estable a largo plazo. Los tres tipos tampoco presentan una tendencia notable. Esto indica que no hubo una expansión de ese mercado medido por el número de agentes que participan en él. Si analizamos los valores de las tres clases de transacciones y su participación en el total (véase gráfica 6) también notamos un estancamiento del nivel de montos de las pequeñas y medianas, aunque la participación porcentual de las transacciones por encima de 10000 pesos aumentó significativamente.

Sobre las grandes transacciones es importante señalar que el intervalo de valores se ubicó entre un mínimo de 10000 y un máximo de 43000 pesos en $1788 .{ }^{18}$ Sin embargo, es claro que por las notarías de la capital no pasaban las grandes transacciones de importación. Al analizar las cifras de los conciertos de alcabalas, que era una forma de fraccionar el pago del impuesto, observamos que existieron transacciones muy por encima del rango de las notarías. ${ }^{19}$ En efecto, tenemos un máximo de 144958 pesos que indica, por lo demás, un nivel de concentración mayor de este mercado, aunque es necesario utilizar de manera más contundente fuentes alcabalatorias -de Santafé y de los centros de distribución interna como Honda y Mompox- para examinar si el decreto de libre comercio contribuyó a expandir el número de comerciantes involucrados en este mercado.

$\mathrm{Al}$ examinar los valores promedio de las transacciones (gráficas 7 y 8), estos indican que existió una disminución perceptible en la media de las transacciones pequeñas mientras que las medianas y grandes se mantuvieron estables. Si sometemos una vez los números a la prueba $t$ de Student, es claro que la media no varió significativamente incluso para las transacciones pequeñas. De hecho, la DS es bastante volátil en algunos años, llegando a representar casi $50 \%$ de la media. Así, los préstamos promedio se ubicaron en 3500 pesos para las transacciones medias y 500 pesos para las pequeñas. Estos resultados indican que la disposición de los comerciantes a conceder créditos para bienes importados, a pesar de la reducción de la tasa de interés, no se explica por una disminución en los montos promedios de esas transacciones.

Pasemos ahora al mercado monetario donde también hemos dividido el mercado en tres tipos de transacciones con los mismos intervalos del

${ }^{18}$ (1788). Notaría Segunda (t. 168, fs. 168-169v.). Archivo General de la Nación. Bogotá, Colombia.

${ }_{19}$ (1789) Real Hacienda Cuentas (fraccionamiento realizado por el comerciante Tomás Ramírez, anexo 3, 1823-c, 1988-c, 390-c, 2129-c, 1269-c). Archivo General de la Nación, Bogotá, Colombia. 


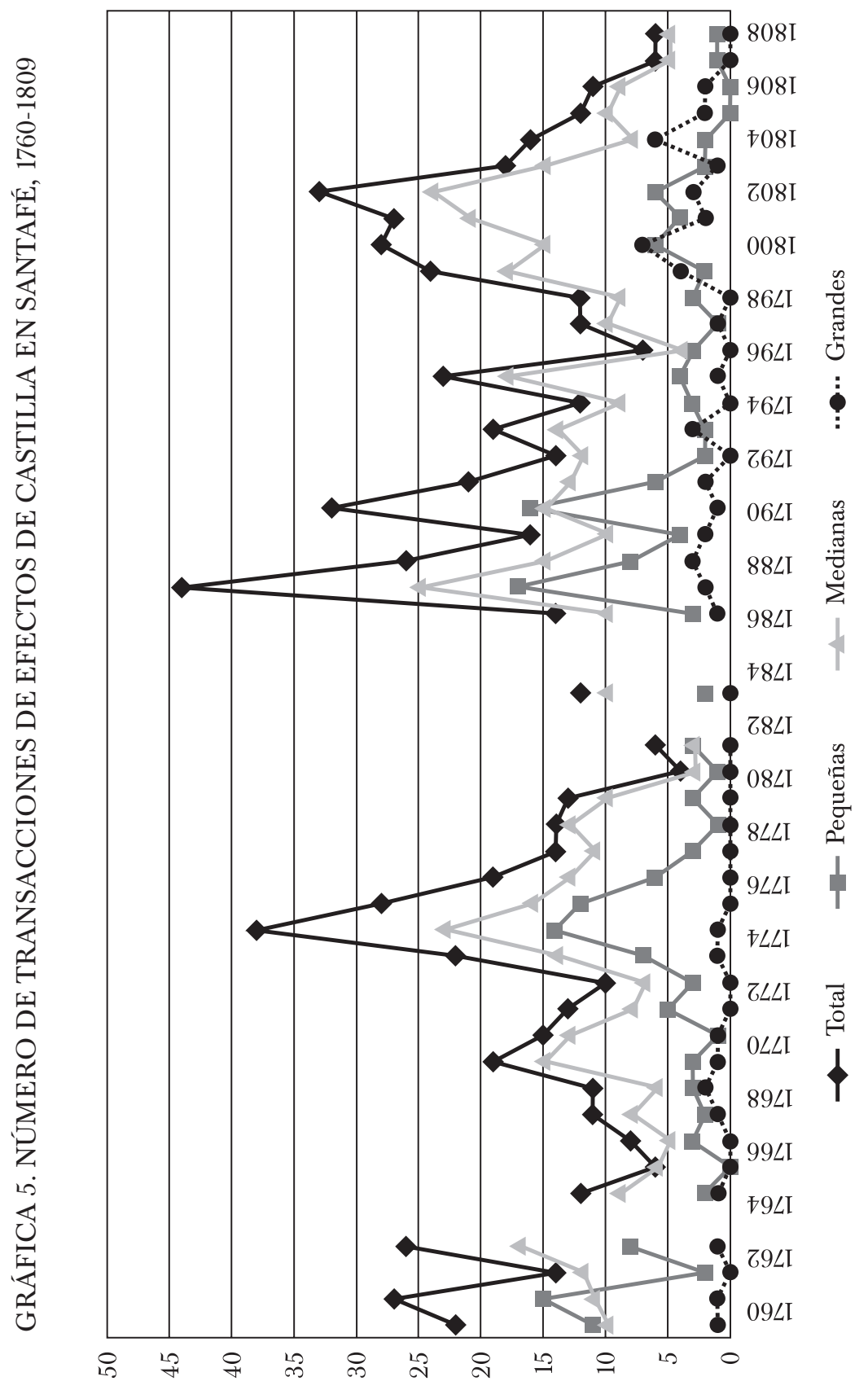

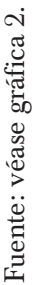




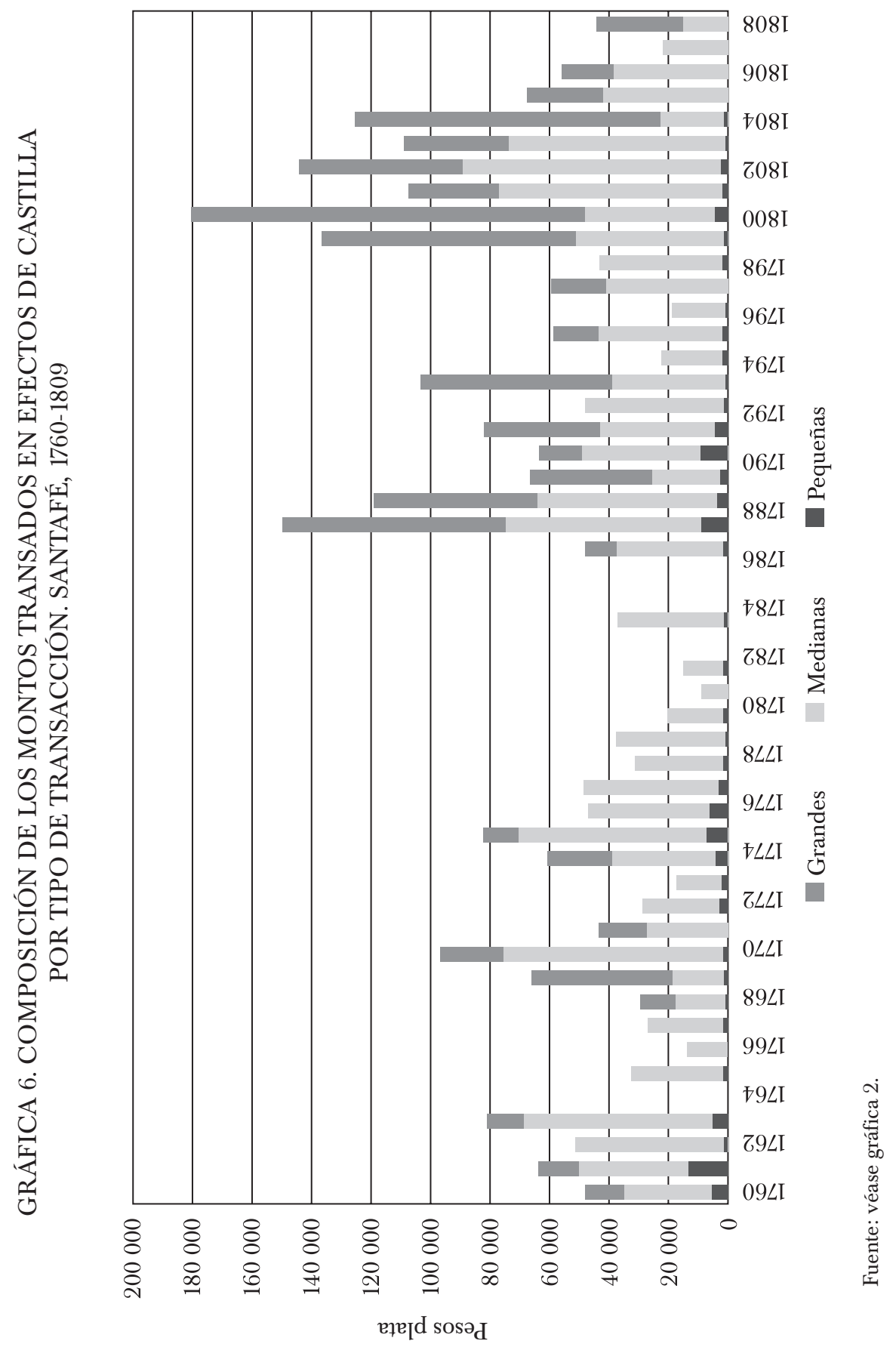




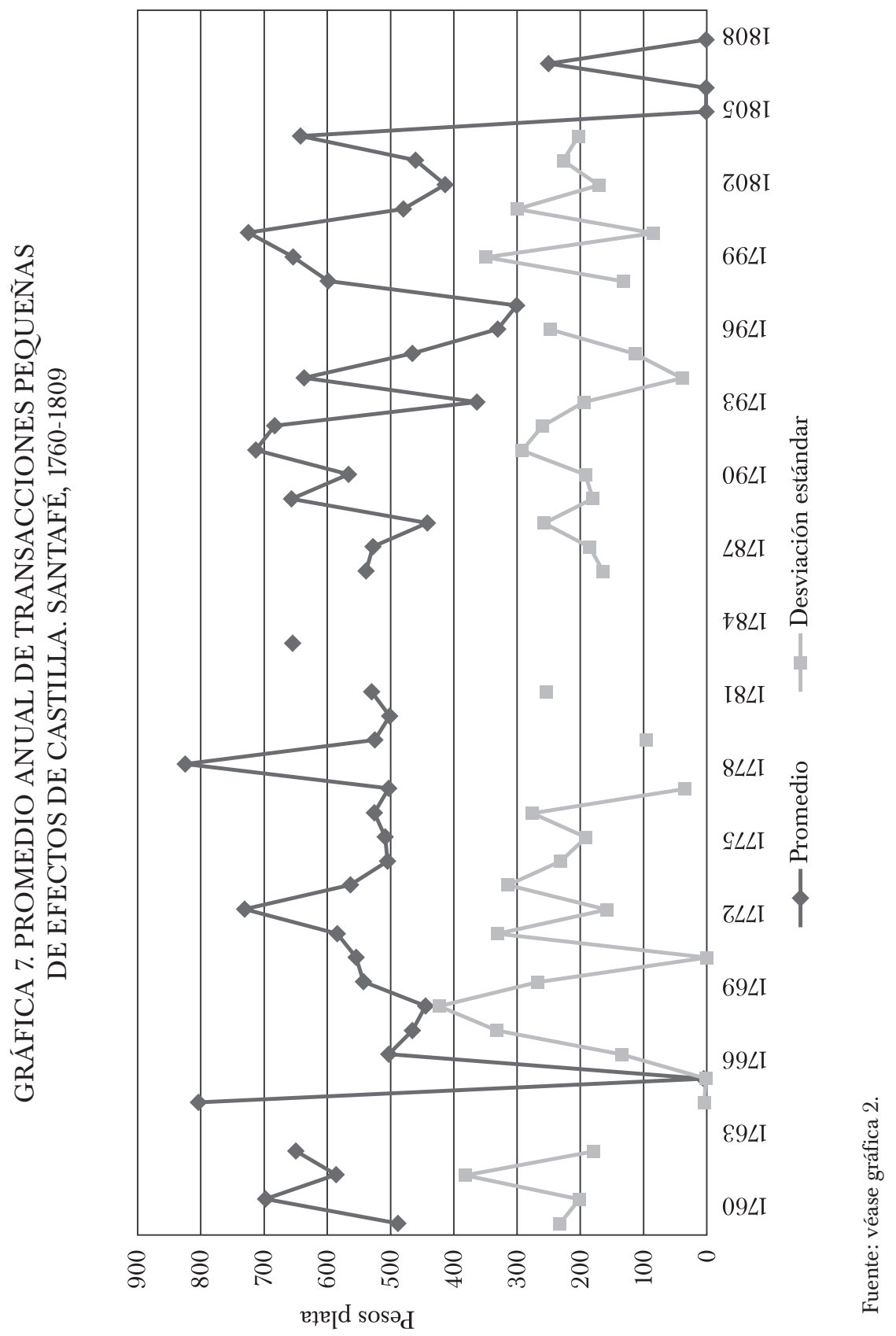




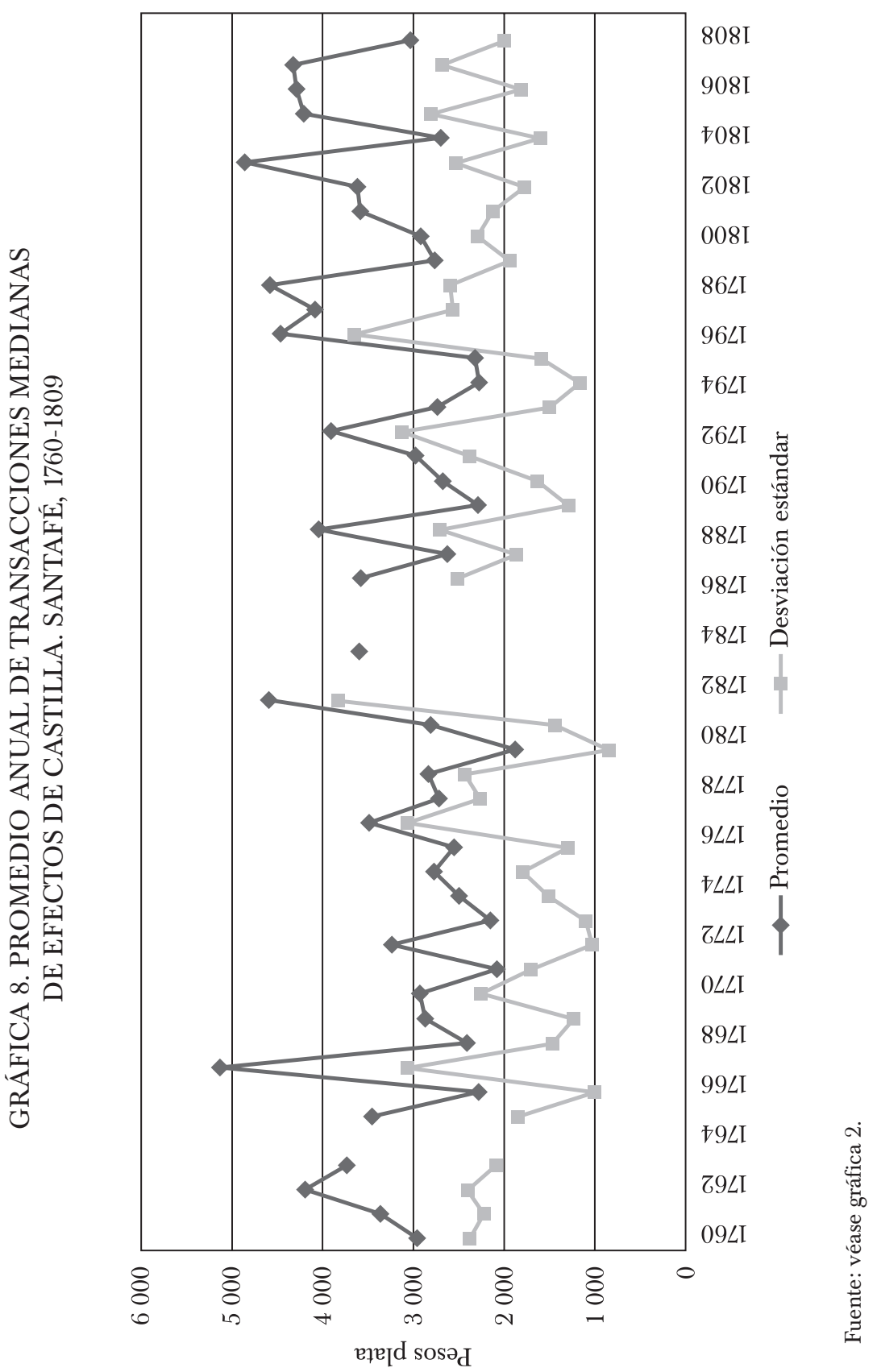


mercado de efectos de Castilla. Al observar el número de transacciones anuales, es notable su crecimiento a nivel agregado (véase gráfica 9). Así, se llega a triplicar el número de transacciones a fines de siglo respecto a la década de 1760. Al observar el comportamiento individual de la plata, es mayor el número de transacciones con este metal, aunque el oro presentó un leve incremento a fines de siglo. Si analizamos el mismo comportamiento por el valor de las transacciones, también es notorio que la plata se utilizaba para créditos pequeños y medianos y sólo a fines de siglo se presentan préstamos mayores a 10000 pesos; en cambio, si observamos el metal amarillo, encontramos un mayor peso de las grandes transacciones -superando 50\% del total-, aunque también fueron importantes las medianas (40\%). Esto no es nada nuevo: la plata y el oro exhiben divisiones funcionales precisas en las transacciones comerciales, correspondiendo a la primera servir en las transacciones pequeñas y medianas y al segundo en grandes operaciones. Sorprende, con todo, la importante cantidad de oro en transacciones medianas.

El comportamiento de los promedios nos indica, en el caso de la plata, que la media de las transacciones pequeñas se incrementa y la DS así lo confirma (gráfica 10). Las medianas presentan un comportamiento diferente, pues los promedios tienden a estancarse y también lo confirma su respectiva DS (gráfica 11). Con el metal amarillo, la media de las transacciones medianas aumentó y la prueba $t$ de Student nos señala que existió un cambio en los promedios (gráfica 12). Así, pasamos de una media de 2766 pesos anuales antes de 1780 a 3989 pesos en el periodo 1785-1805. Para los montos de las grandes transacciones la muestra no permite hacer ninguna consideración consistente. Sin embargo, es notorio el aumento del promedio en al menos dos tipos de transacciones. Esto nos indica que los comerciantes estuvieron dispuestos a prestar mayores cantidades a cada deudor lo que, por otra parte, indica que el tamaño promedio de los capitales prestados no explica la mayor disposición a prestar de los comerciantes a pesar de una reducción de la tasa de interés nominal y real.

Examinemos ahora las variables relacionadas con el tiempo. ¿Qué podemos decir sobre la evolución de los plazos? La primera constatación es que, si tomamos un promedio simple anual de todos los préstamos -divididos, una vez más, en tres tipos de transacciones-, los promedios y sus medidas de dispersión son más homogéneas que en el análisis de los montos y el número de casos. Esto indica que existían unos plazos más o menos tradicionales en torno a unas cantidades determinadas. Ignoramos la razón de este comportamiento; quizá se deba a la costumbre en las prácticas crediticias. No obstante, también se observa la misma situación en otros espacios coloniales (Mata, 1996; Kickza, 1998; Cavieres, 1996). 


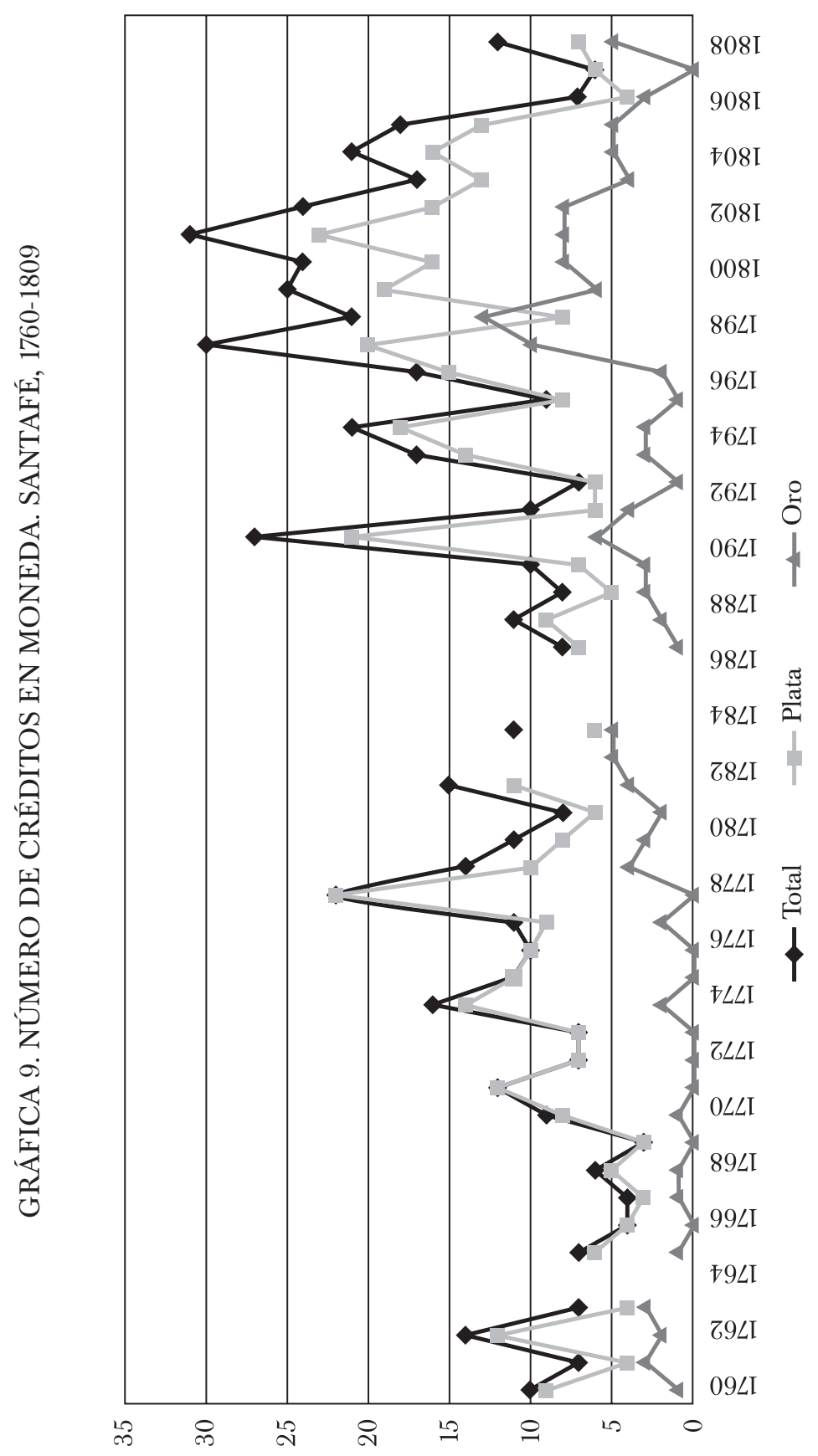

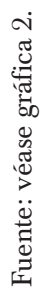




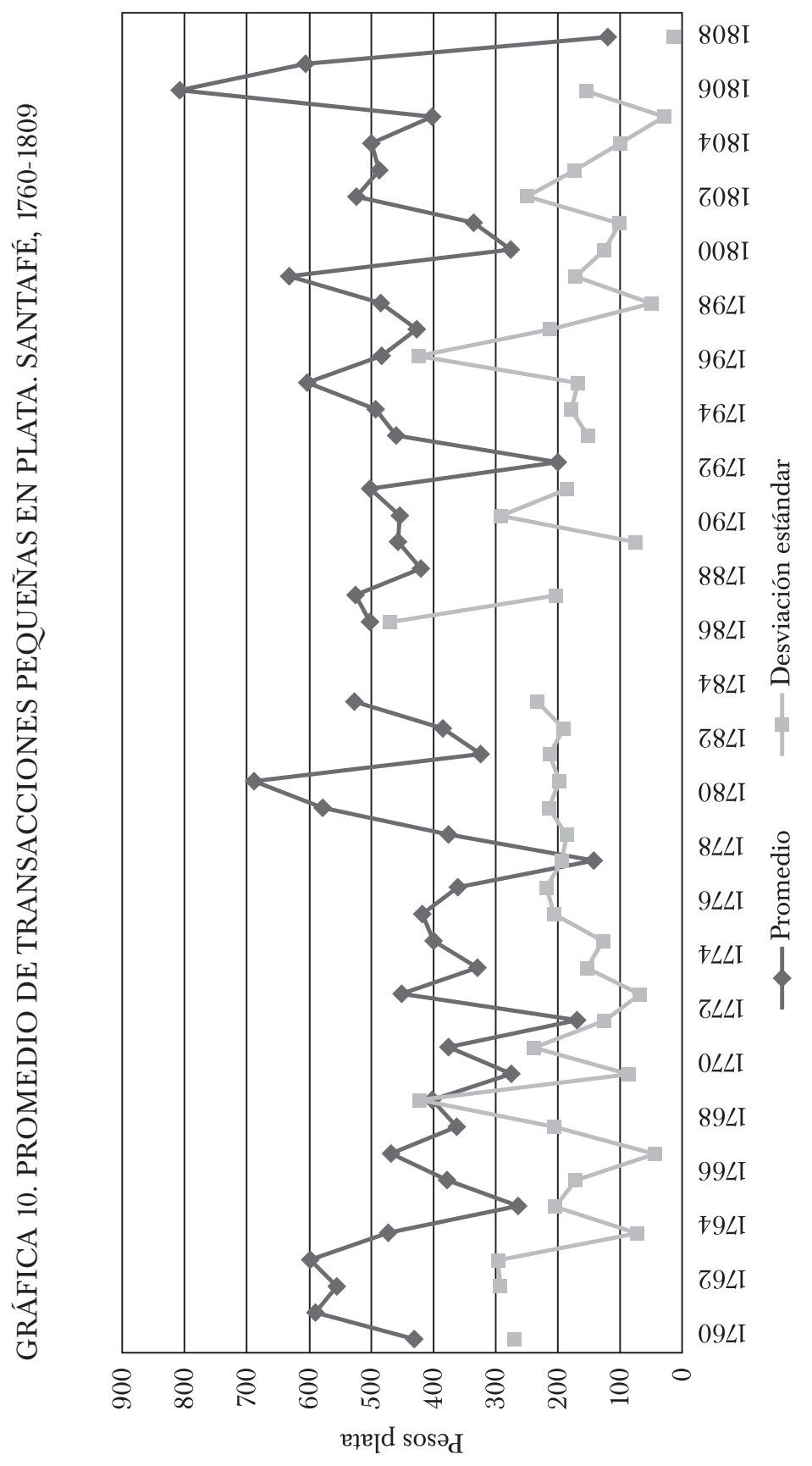

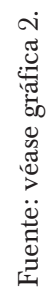




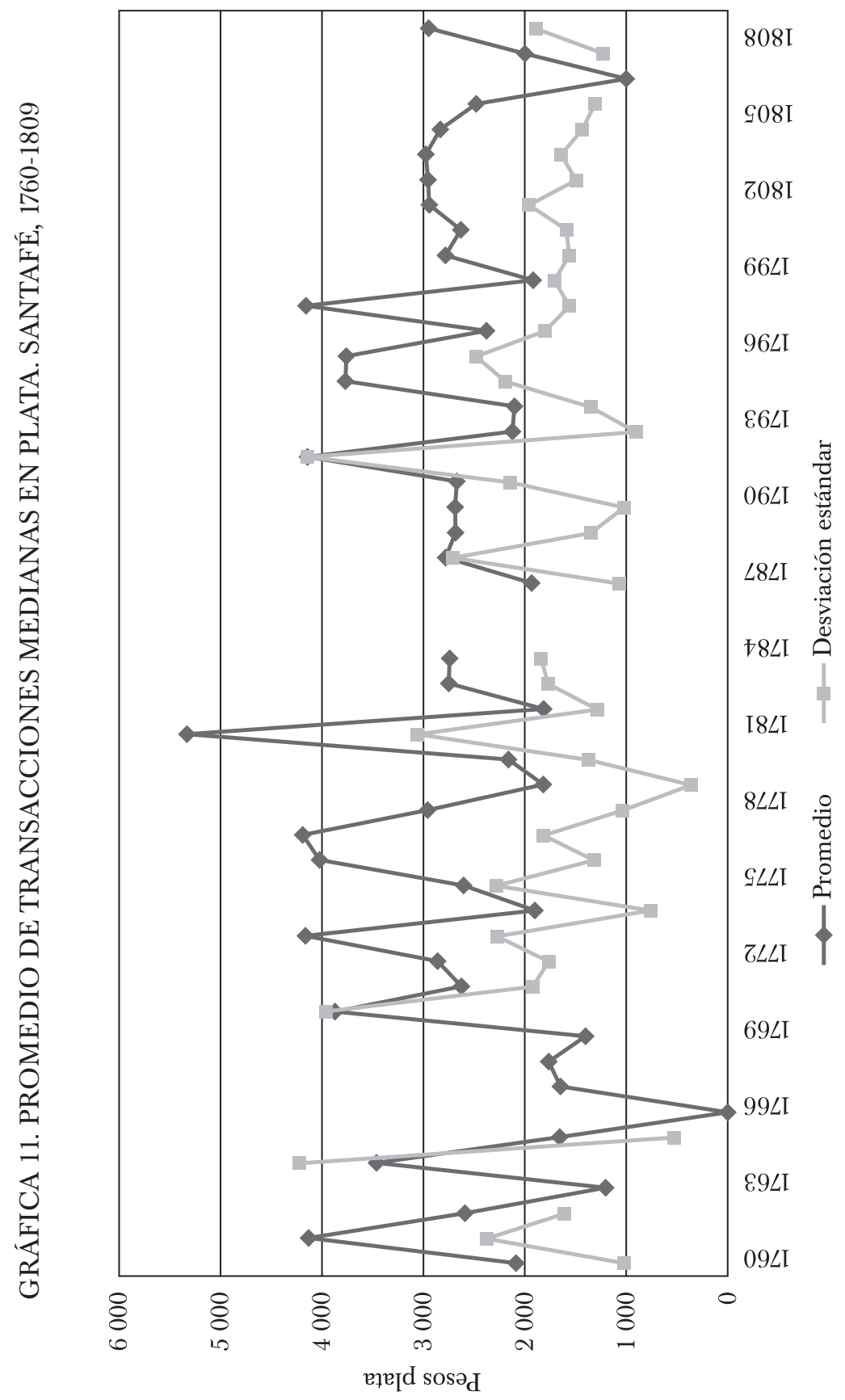

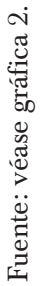




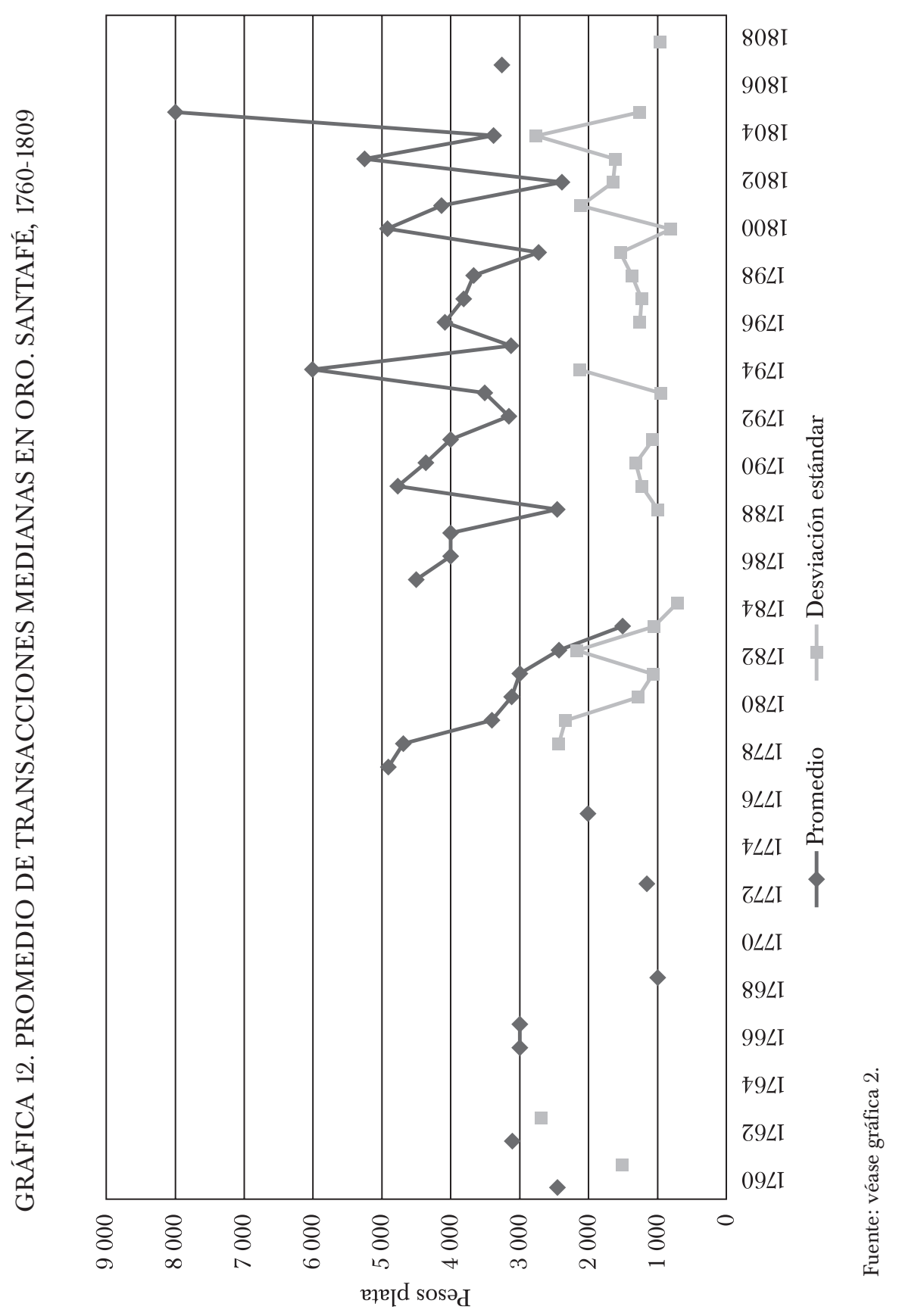


Observemos las gráficas 13 y 14 donde clasificamos los plazos para ambos mercados y realicemos comparaciones entre los promedios de los periodos 1760-1780 y 1781-1809. Podemos extraer al menos tres consideraciones con base en estos datos: a) los plazos en el mercado monetario son en promedio menores que aquellos dados en el mercado de efectos de Castilla, b) los plazos en ambos mercados sufrieron reducciones importantes, y c) el oro presenta plazos mayores que la plata, aunque la disminución en el primero fue más acelerada.

De esta manera, de plazos mayores a 20 meses en el primer periodo en el mercado de grandes transacciones de efectos, en el mercado del oro tenemos plazos de 16 meses. Ambos plazos disminuyen sensiblemente en el siguiente periodo, aunque la diferencia entre ambas series sigue siendo de tres meses. En cuanto a las transacciones medianas pasamos de un promedio de 9.8 a 8.2 meses en el mercado de la plata y de 11.2 a 8.5 en el del oro. En el mercado de efectos de Castilla, pasamos de 12.3 a 10.1 meses en el periodo siguiente. En las transacciones pequeñas, finalmente, la reducción fue de 7.6 a 6.2 meses en el mercado monetario de plata y de 8.4 a 7.9 en el mercado de efectos de Castilla.

Resulta razonable que la moneda, un bien escaso y con un importante grado de liquidez, presentara menores plazos que los créditos para ventas de efectos de Castilla. Sin embargo, es importante llamar la atención sobre la reducción global en los plazos y su posible impacto en ambos mercados. Del lado de la oferta, la reducción significa un aumento en la expectativa de rotación del capital. La incidencia de la disminución en la demanda depende, sin embargo, de la capacidad de sustitución de esos créditos y del estado mismo de la economía. Así, es claro que los créditos eclesiásticos tienen mayores plazos. De hecho, en Pamplona Carmen Adriana Ferreira (1999) señala que "de los 588 censos otorgados en la provincia, 38.6\% lo redimió en menos de 6 años" (p. 71). Así, un alto número de deudores esperaba redimir sus pasivos en plazos mayores a seis años, términos mucho mayores de los que se acostumbraban para el crédito con los comerciantes. Examinemos, entonces, la tasa de impago de los créditos comerciales.

Los documentos notariales presentan un dato importante para un análisis de la tasa de impago de esos créditos. En efecto, perpendicularmente a cada escritura, se escribía la fecha de redención de cada obligación. Así, cuando no aparece dicha fecha, es claro que no hubo pago, se renegoció la deuda o, sencillamente, que el pago se exigió por vía judicial con todos sus costos adicionales. La gráfica 15 resume los datos sobre la tasa de impago. Los datos sobre tales tasas para efectos de Castilla es bastante estática. En efecto, la cantidad de escrituras canceladas sólo llegó a 56\%, para el periodo $1760-1780$ y pasó a $52 \%$ en el periodo $1781-1805$, aun teniendo 


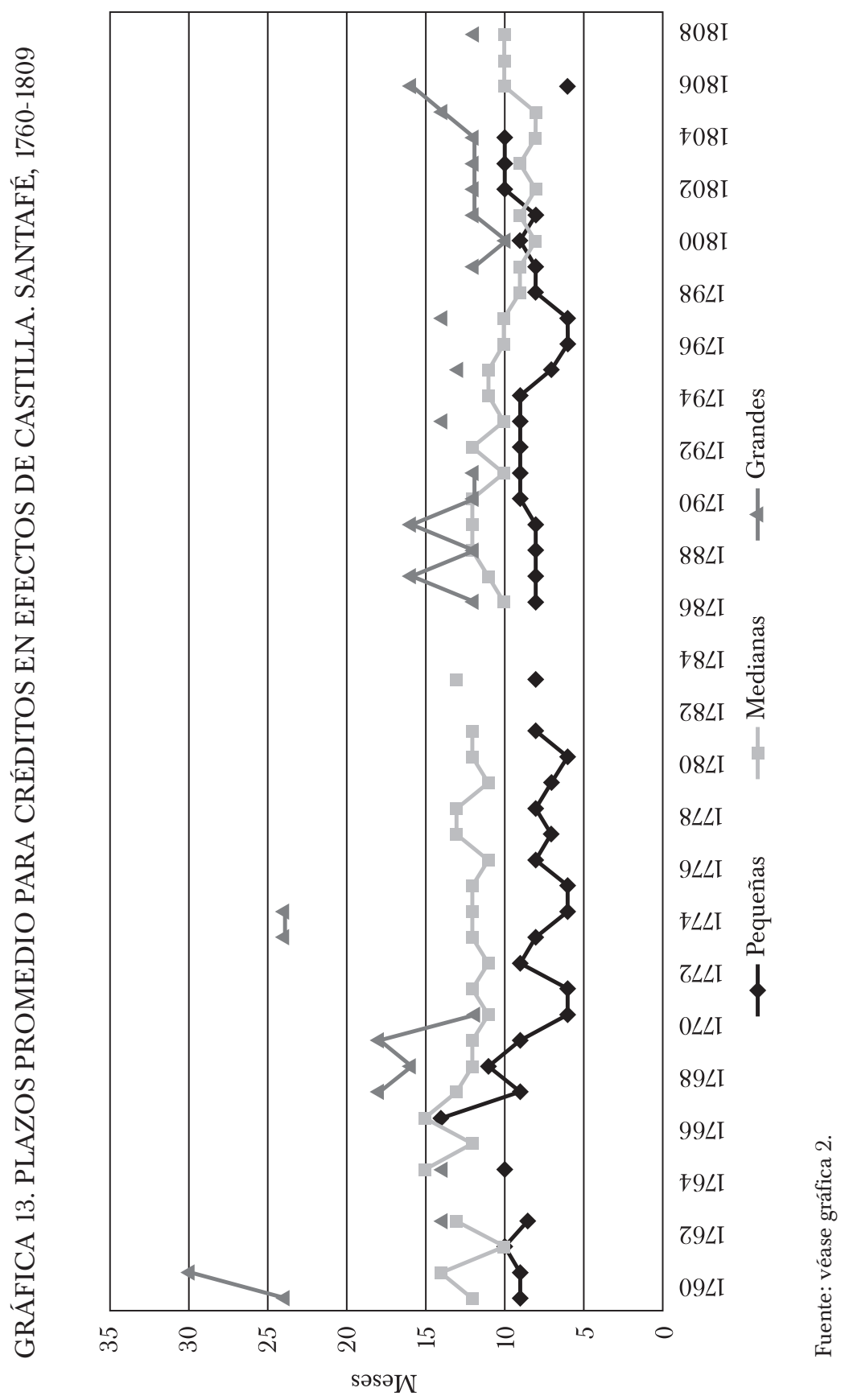




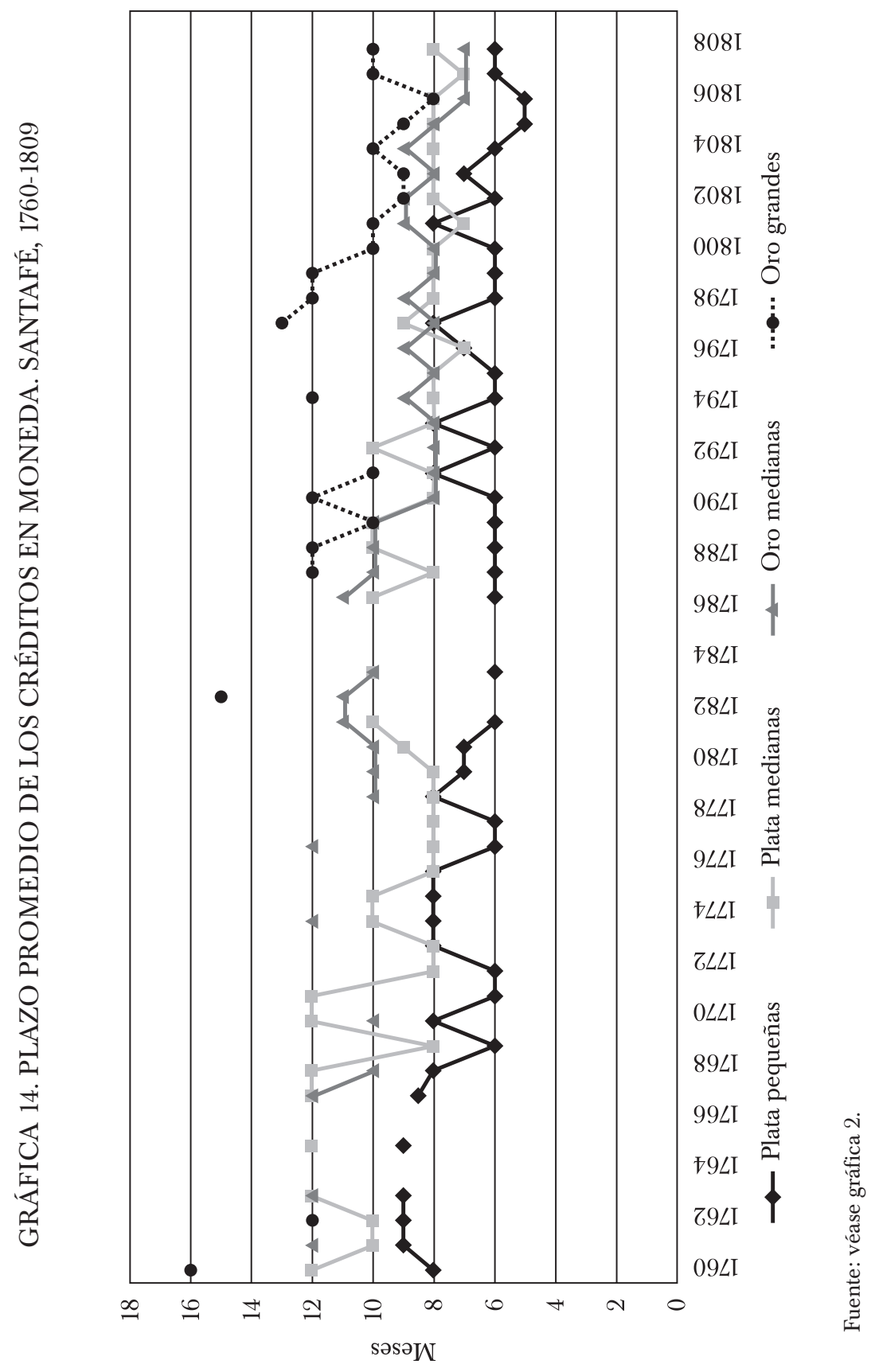




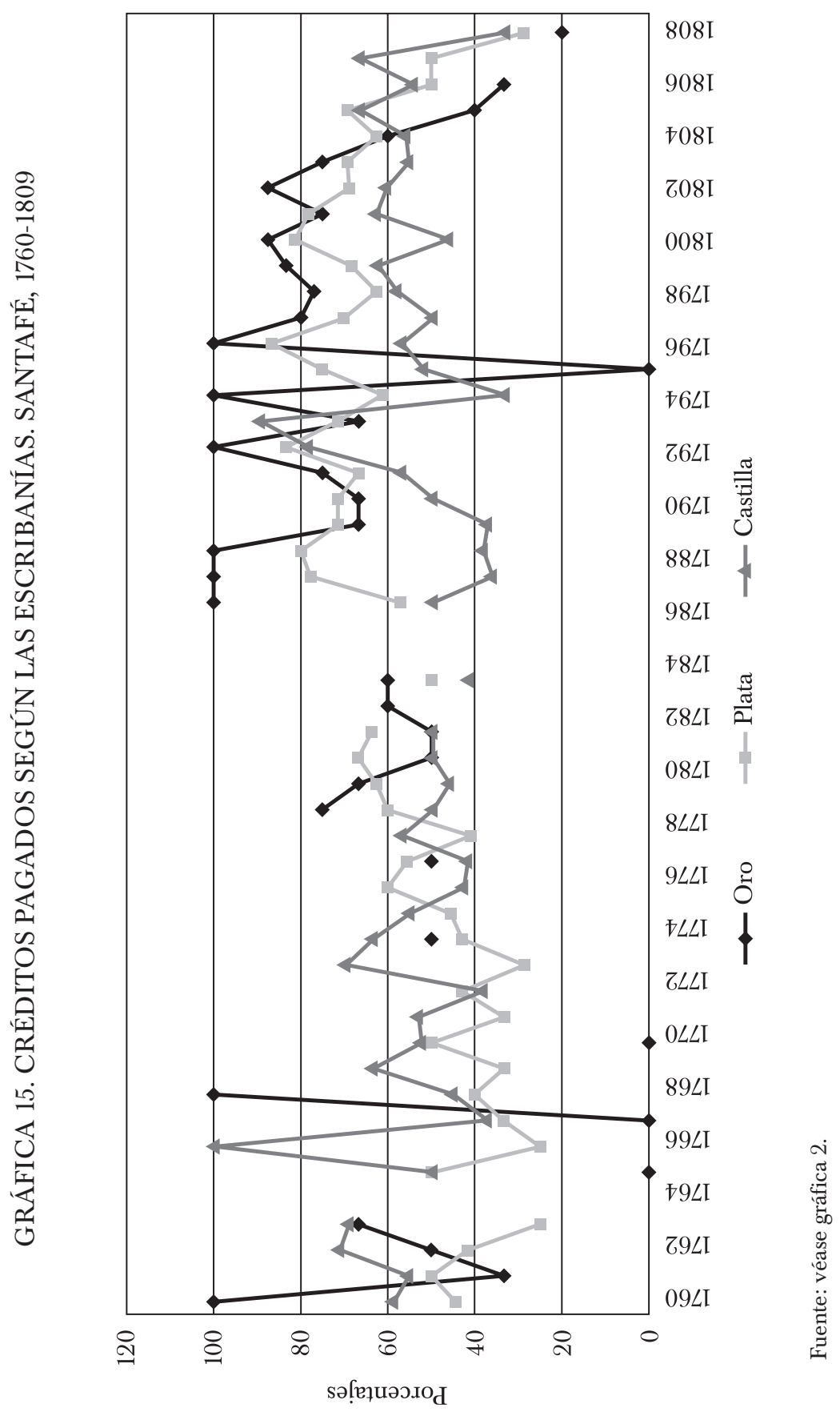


en cuenta los importantes datos residuales que empujaban hacia arriba el promedio.

Esta situación contrasta con lo sucedido en el mercado monetario, donde la tasa de impago disminuye sensiblemente. En efecto, para el periodo $1760-1780$ sólo $41 \%$ de los créditos en plata fue cancelado, y para el periodo $1781-1805$, la tasa se incrementó en un promedio de $70.1 \%$. Los créditos en metal amarillo, por su parte, se pagaron en 45 y $75.4 \%$, respectivamente.

Los datos anteriores muestran la diferencia entre los dos tipos de mercados. Mientras el de bienes de Castilla se mantuvo estático, el monetario redujo sus riesgos de impago. Esto explica parcialmente el aumento en la oferta de fondos prestables y el aumento en la tasa de rotación del capital dada la reducción en los plazos. La demanda, a pesar de la reducción de estos, respondió positivamente y aumentó la tasa de créditos cancelados, síntoma de mejoría en el sector real. Con todo, es importante enfatizar que una tercera parte de esos créditos seguía sin pagarse, lo que muestra efectivamente el alto riesgo de estas inversiones en una economía preindustrial. Además, cuando se compraban efectos de Castilla, existía una alta probabilidad de que el pago se hiciera luego del plazo estipulado y, por tanto, de que se pagasen intereses. De hecho, no resulta sorprendente que todos los libros de comerciantes, desde Nueva España hasta Chile, presenten cuentas pormenorizadas de "cuentas incobrables" (Brading, 1995).

Para finalizar esta sección, permítasenos abordar un último aspecto: la tasa interna de retorno (TIR) de esos créditos. Como se sabe, se suele calcular la rentabilidad de una inversión con base en el ingreso final. No obstante, la TIR es más precisa, pues mide el flujo de caja de la inversión. Afortunadamente las escrituras también nos permiten analizar este indicador a partir de la forma de pago estipulada en la escritura.

De esta manera, algunos créditos se pactaban para ser pagados en abonos semanales, mensuales e incluso anuales, cuando el horizonte temporal era elevado. Hemos podido examinar qué importancia tuvo este tipo de avances en el total de créditos ofrecidos. Es necesario anotar que existen ciertas escrituras que escapan a nuestro análisis de los plazos y la TIR como aquellos pagos que no establecían un plazo exacto para cubrir la obligación; por ejemplo, aquellos que acordaban la liquidación "cuando le vaya llegando la plata" o cuando se terminara un "pleito en la Real Audiencia". ${ }^{20}$ Estos datos, sin embargo, sólo representan $8.7 \%$ de toda nuestra muestra. Después de todo, no acordar tiempos exactos de liquidación elevaba el riesgo de impago.

${ }^{20}$ (1776). Notaría Segunda (t. 154, fs. 250-250v). Archivo General de la Nación. Bogotá, Colombia. 
Iniciando por el mercado de bienes de Castilla, observamos que la modalidad de crédito con avances se presentó con particular importancia en las pequeñas y medianas transacciones. Para el periodo 1760-1780, $73.4 \%$ de las pequeñas transacciones se pactó en estas condiciones, $53.4 \%$ de las medianas y $38.5 \%$ de las grandes operaciones. Para el periodo 17811805, las tendencias son similares, con una participación de 79.6, 61 y $48.3 \%$, respectivamente. Así, es claro que en las grandes transacciones el crecimiento fue notable. En el caso del mercado monetario, las transacciones presentan un encuadre diferente. Para el primer periodo sólo 33.4\% de las pequeñas transacciones se pactó con este tipo de pagos, $52 \%$ de las medianas y $47 \%$ de las grandes operaciones. Sin embargo, el crecimiento fue mayor, pues para 1781-1805 tenemos participaciones de 51, 63 y 68\%, respectivamente.

Estos datos nos llaman la atención sobre varios puntos. En primer lugar, es notable la alta participación de avances en las pequeñas transacciones de efectos de Castilla. Esto, por cierto, sólo confirma para Nueva Granada una estructura de crédito que se daba en la mayoría de pulperías y pequeños negocios de la economía colonial (Romano, 2004). En segundo lugar, el aumento de este tipo de créditos en el mercado monetario y su relación con las tasas de impago que hemos examinado anteriormente nos señalan que hubo un aumento de la TIR del mercado de monetario y no en el de efectos de Castilla; ello refuerza nuestro argumento de que el primer mercado fue cada vez más atractivo para aquellos comerciantes con la suficiente liquidez.

\section{CONSIDERACIONES FINALES}

En estas consideraciones tendremos la oportunidad de poner en perspectiva todos los datos hasta aquí presentados. Hemos agobiado al lector con una serie de descripciones técnicas, quizá mecánicas. No obstante, era un ejercicio necesario; de otra manera, nuestras hipótesis carecerían de sentido.

Empecemos por el lado de la oferta. La primera constatación importante es la reducción de las diferentes tasas de interés y, en particular, de la reducción de la tasa para los créditos comerciales. Hemos visto que la oferta de crédito presentó cierto grado de elasticidad frente a la tasa de interés. Esto indica que la reducción forzosa de la tasa redujo la oferta al inicio de nuestro periodo, aunque el aumento acelerado del crédito a fines de siglo indica que buena parte de los comerciantes estaba dispuesta a prestar por debajo de la tasa techo impuesta por la Real Audiencia. 
¿Qué explica este comportamiento de la oferta? En primer lugar, un conjunto de variables indica que el mercado monetario aumentó sus incentivos para los comerciantes que se dedicaban al mercado de importación. Una reducción importante en los plazos, un incremento de la tasa de retorno y una disminución del riesgo de impago indican un aumento en la tasa de rotación de capital y un descenso del riesgo y los costos de transacción. Entre tanto, el mercado de bienes importados mostró un notable estancamiento en estas variables. Así, el costo de oportunidad del mercado monetario disminuyó notablemente.

Lo anterior nos conduce, igualmente, a una consideración importante: nuestros datos no nos permiten inferir que las guerras de la segunda mitad de siglo hayan aumentado los incentivos para prestar más moneda (tesis sugerida, entre otros, por Gelman, 1990). En efecto, no observamos que a una depresión en el mercado de importación causada por el cierre de los puertos, la haya seguido un aumento de los créditos en metálico. Por ejemplo, la mayor fase de expansión de los créditos en moneda inicia en 1784, justo después de reabierto el comercio. La explicación, insistimos, está en la estructura misma de la actividad comercial que mejoró algunas variables del mercado monetario y las mantuvo estancadas en el mercado de importación.

Ahora bien, ¿qué posibilitó que estas variables en el mercado metálico hayan mejorado a fines del periodo colonial? La respuesta no es fácil y sólo podemos ofrecer unas hipótesis preliminares. La primera nos conduce sin duda a las instituciones. En los últimos años existe una importante tradición historiográfica que ha hecho énfasis en las "reglas de juego" para explicar el crecimiento económico (Coatsworth y Tortella, 2007; North, 1983). En Colombia este enfoque ha sido remarcado por Salomón Kalmanovitz (2010). En el caso del sector comercial, el desarrollo de instituciones como el consulado y sus antecedentes habría disminuido el riesgo y los costos de transacción (Hausberger e Ibarra, 2003). En el caso neogranadino, es importante analizar el impacto del Tribunal de Comercio, primero, y del Consulado después (Lucena, 1986). No nos referimos al influjo de inversiones que desarrolló el consulado en donde existe un debate muy parcial sobre su fracaso o éxito (McFarlane, 1983; Múnera, 1998). En cambio, sí aludimos a la necesidad de establecer su impacto en la protección de los derechos de propiedad y la agilidad en el arbitraje de los pleitos.

Una segunda hipótesis es la consolidación por parte de los comerciantes de redes de distinto tipo para reducir los costos de transacción (Ibarra y Valle, 2007). En un trabajo reciente, se logró construir la red de los comerciantes de Santafé para algunos años puntuales a partir de los apoderados. Por supuesto, la red no habla por sí sola. Lo que nos interesa señalar es la densidad y su diferencia frente a los primeros años del periodo aquí es- 
tudiado (Torres, 2012, cap. 1). Así, consideramos que la consolidación de diversas redes de los comerciantes capitalinos explica en parte la mejoría de las variables aquí estudiadas y, por lo tanto, revela la disposición de los comerciantes a prestar más dinero.

Del lado de la demanda es fundamental señalar que, aunque no podemos establecer el grado de elasticidad frente a la reducción de la tasa de interés, es claro que el crédito comercial empezó a ser una alternativa importante al crédito eclesiástico. Para comenzar, las tasas llegaron a ser similares y, a pesar de la reducción de los plazos y el aumento en la tasa de retorno, los deudores comenzaron a pagar sus deudas de manera expedita. Además, deben tenerse en cuenta dos ventajas que ofrecía este tipo de crédito: a) el gravamen recaía sobre la persona y no sobre el colateral, b) se daba mayor importancia al fiador que a los bienes que respaldaban la deuda. Esto explica por qué los documentos notariales, en general, no puntualizan los bienes del deudor pero sí prestaban especial importancia a los fiadores. De hecho, Mata (1996) señala que "el crédito mercantil se caracterizaba por la inexistencia casi generalizada de hipotecas de bienes raíces" (p. 154). Esto abría el mercado para un mayor número de personas sin la tenencia de bienes raíces.

Por otra parte, ¿por qué las variables del mercado de importación se estancaron? Aquí, una vez más, nos mantenemos en un terreno hipotético. Es claro, con todo, que el comercio libre no explica el fenómeno pues, precisamente, no alteró esa condición de estancamiento. La respuesta puede estar en la función de consumo de las mercancías de importación con sus restricciones clásicas, como el ingreso y la elasticidad de sustitución, y otras menos clásicas como las preferencias y ese complejo conjunto de estrategias que Albert Hirschman (1977) identificó como la salida (dejar de consumir), la voz (protestar como consumidor) o la lealtad (mantenerse en consumo). Xabier Lamikiz (2007) ha señalado que el consumidor colonial empezó a tener cada vez más capacidad de agencia frente al vendedor, pidiendo más variedad y mejor calidad. En cambio, del lado de la oferta, la competencia desde el decreto de los navíos de registro se hacía cada vez más feroz. Quizá, en Nueva Granada, esa competencia es más palpable con el secular enfrentamiento entre Santafé y Cartagena por el mercado interior. Por eso observamos que en el mercado de importación las tasas de impago, la TIR y otras variables se mantienen estables. Pero esto, insistimos, requiere mayor investigación. Lo que está fuera de duda es que la reducción en la tasa de interés pudo reducir la rentabilidad del comercio de importación a menos que se presentara un aumento en las cantidades vendidas y sus precios.

Para volver al crédito comercial, ¿̇qué podemos decir sobre el destino de esos fondos? Infortunadamente, es imposible establecer qué cantidades 
fueron destinadas al consumo y cuáles a la inversión y así establecer si el impacto positivo de esos préstamos se presentó en el corto o en el largo plazo. En todo caso, no perdamos de vista el importante incremento de su participación en el PIB. Igualmente, es necesaria una suerte de sociología del crédito que nos ayude a entender el destino final de esos fondos en términos sectoriales.

Finalmente, es importante reiterar la necesidad de tener en cuenta estos datos a la hora de analizar de manera agregada la economía. Hemos insistido en que el crédito se aceleró a fines de siglo y, seguramente, fue una de las causas del crecimiento económico. Sin embargo, su evolución también nos indica una reducción en los últimos años del periodo colonial: ¿Se trata, acaso, de un signo de desaceleración de la economía? Es, por supuesto, una interrogante para investigaciones posteriores.

\section{LISTA DE REFERENCIAS}

Bauer, A. (1983). The Church in the economy of Spanish America: Censos and depósitos in the eighteen and nineteenth centuries. Hispanic American Historical Review, 63(4), 707-733.

Bell, A., Brooks, Ch., y MoOre, T. (diciembre, 2008). Interest in medieval accounts: Examples from England, 1272-1340. Social Science Research Network. http://dx.doi. org/10.2139/ssrn.1318333.

Bohórquez, J. y PALACio, G. (2008). La circulación y el consumo en las cuencas del río Sogamoso y Lebrija: comerciantes y consumidores en el siglo XVIII. Historia Crítica, 35, 176-200.

Bordo, M. y Cortés, R. (2001). Introduction. En M. Bordo y R. Cortés (eds.), Transferring wealth and power from the Old to the New World (pp. 1-16). Cambridge: Cambridge University Press.

Brading, D. (1995). Mineros y comerciantes en el México borbónico (1763-1810). México: Fondo de Cultura Económica.

Castro, H. y Montoya, J. J. (2009). Poder y religión en la ejecución de censos. El convento de la Concepción de Santafé (1739-1810). Ponencia presentada en el II Congreso Latinoamericano de Historia Económica, México.

Cavieres, E. (1996). Del crédito tradicional colonial al crédito moderno. Perspectivas y fuentes. Chile: el crédito en la periferia. América Latina en la Historia Económica, 3(6), 9-19.

Coatsworth, J. y Tortella, G. (2007). Instituciones y desempeño económico a largo plazo en México y España (1800-2000). En R. Dorado et al. (eds.), México y España, ¿historias económicas paralelas? (pp. 47-76). México: Fondo de Cultura Económica. 
Am. Lat. Hist. Econ., año 21, núm. 3, septiembre-diciembre, 2014, pp. 9-45

Colmenares, G. (1997a). Cali: terratenientes, mineros y comerciantes-siglo XVIII. Bogotá: Tercer Mundo.

Colmenares, G. (1997b). Historia económica y social de Colombia. Popayán: una sociedad esclavista, 1680-1800. Cali: Universidad del Valle.

DazA, V. (2009). Los marqueses de Santa Coa: una historia económica del Caribe colombiano. Bogotá: Instituto Colombiano de Antropología e Historia.

Ferreira, C. A. (1999). El crédito colonial en la provincia de Pamplona, Nueva Granada: uso del censo consignativo. Signos Históricos, 1(1), 59-84.

Gelman, J. (1987). El gran comerciante y el sentido de la circulación monetaria en el Río de la Plata colonial tardío. Revista de Historia Económica, 5(3), 485-507.

Gelman, J. (1990). Venta al contado, venta a crédito y crédito monetario en América colonial: acerca de un gran comerciante del virreinato del Río de la Plata. Jahrbuchfür Geschichte Lateinamerikas, 27, 101-126.

Hausberger, B. e Ibarra, A. (2003). Los consulados hispanoamericanos como tema. En B. Hausberger y A. Ibarra (eds.), Comercio y poder en América colonial. Los consulados de comerciantes, siglos XVII-XIX (pp. 7-14). Madrid: Iberoamericana.

Hirschman, A. (1977). Salida voz y lealtad. Respuestas al deterioro de empresas, organizaciones y estados. México: Fondo de Cultura Económica.

IBARRA, A. y VALLE, G. DEL (comps.). (2007). Redes sociales e instituciones comerciales en el Imperio español, siglos XVII a XIX. México: Instituto de Investigaciones Dr. José María Luis Mora.

Kalmanovitz, S. (2006). El PIB de la Nueva Granada en 1800: auge colonial estancamiento republicano. Revista de Economía Institucional, 8(15), 161-183.

Kalmanovitz, S. (2008). Las consecuencias económicas de la Independencia en Colombia. Revista de Economía Institucional, 10(19), 207-233.

Kalmanovitz, S. (2010). Nueva historia económica de Colombia. Bogotá: Santillana.

KICKZA, J. (1998). El crédito mercantil en Nueva España. En M. P. MarTínez y G. DEL VAlle (comps.), El crédito en Nueva España (pp. 33-60). México: Instituto de Investigaciones Dr. José María Luis Mora/El Colegio de Michoacán.

LAmikiz, X. (2007). Patrones de comercio y flujo de información comercial entre España y América durante el siglo XVIII. Revista de Historia Económica, 25(2), 231-358.

Lucena, M. (1986). Los precedentes del consulado de Cartagena: el consulado de Santafé (1695-1713) y el Tribunal de Comercio cartagenero. Estudios de Historia Social y Económica de América, 2, 179-198.

Ludlow, L. y Silva, J. (eds.). (1993). Los negocios y las ganancias: de la colonia al México moderno. México: Instituto de Investigaciones Dr. José María Luis Mora.

MARICHAL, C. (1997). Obstacles to the development of capital markets in $19^{\text {th }}$ century Mexico. En S. Haber (ed.), How Latin America fell behind (pp. 118-145). Stanford: Stanford University Press.

MARICHAL, C. (1998). La bancarrota del virreinato. Nueva España y las finanzas del imperio español, 1780-1810. México: Fondo de Cultura Económica. 
Martínez, M. P. y VAlle, G. DEL (1998). Los estudios sobre el crédito colonial: problemas, avances y perspectivas. En M. P. MARTínez y G. DEL VAlle (comps.), El crédito en Nueva España (pp. 13-32). México: Instituto de Investigaciones Dr. José María Luis Mora/El Colegio de Michoacán.

Mata, S. (1996). El crédito mercantil. Salta a fines del XVIII. Anuario de Estudios Americanos, 52(2), 147-171.

MCFarlane, A. (1983). Comerciantes y monopolio en la Nueva Granada: el consulado de Cartagena de Indias. Anuario Colombiano de Historia Social y de la Cultura, $11,143-70$.

McFarlane, A. (1997). Colombia antes de la independencia. Bogotá: Banco de la República.

Meisel, A. (2011). Crecimiento, mestizaje y presión fiscal en el virreinato de la Nueva Granada, 1761-1800. Cartagena: Centro de Estudios Regionales.

Meisel, A. y López, A. (1990). Papel moneda, tasas de interés y revaluación durante la regeneración. En A. Meisel et al. (eds.), El Banco de la República. Antecedentes, evolución y estructura (pp. 67-102). Bogotá: Banco de la República.

MúnerA, A. (1998). El fracaso de la nación: región, clase y raza en el Caribe colombiano (17171821). Bogotá: Banco de la República/El Áncora.

Muñoz, E. A. (2010). Alcabalas y actividad económica en Santafé 1780-1821. Estudio presentado a la Comisión Bicentenario de la Independencia de Colombia. Recuperado de http://www.bicentenario.unal.edu.co.

NorTH, D. (1983). Structure and change in economic history. Nueva York: Norton.

OTs, J. M. (1950). Instituciones de gobierno del Nuevo Reino de Granada durante el siglo XVIII. Bogotá: Universidad Nacional de Colombia.

Pedraja, R. (1976). Aspectos del comercio en Cartagena de Indias en el siglo XVIII. Anuario Colombiano de Historia Social y de la Cultura, 8, 107-125.

Pérez, P. (1988). Plata y libranzas. La articulación comercial del México borbónico. México: El Colegio de México.

Pietschmann, H. (1996). Dinero y crédito en la economía mexicana a finales del periodo colonial (1750-1810), reflexiones sobre el estado actual de las investigaciones. Históricas, 47, 27-51.

Plan de una compañía patriótica de comercio. (1801). En L. A. Restrepo (1993). Correo curioso, erudito, económico y mercantil (pp. 107-108). Bogotá: Biblioteca Nacional.

Quiroz, A. (1994). Reassessing the role of credit in late colonial Peru: Censos, escrituras and imposiciones. Hispanic American Historical Review, 74(2), 193-230.

REDD, C. y BEKAR, C. (2003). Religious prohibitions against usury. Explorations in Economic History, 40(4), 347-368.

Restrepo, L. A. (1993). Correo curioso, erudito, económico y mercantil. Bogotá: Biblioteca Nacional.

REYES, C. (2000). Crédito para comerciantes y crédito para consumidor: la diferente conceptualización de la usura en la España del siglo XVIII. En R. TORREs (ed.), Capitalismo mercantil en la España del siglo XVIII (pp. 141-172). Pamplona: Universidad de Navarra. 
Romano, R. (1997). Moneda, pseudomonedas y circulación monetaria en las economías de México. México: Fondo de Cultura Económica.

Romano, R. (2004). Mecanismo y elementos del sistema colonial americano, siglos XVI-XVIII. México: Fondo de Cultura Económica.

Socolow, S. (1991). Los mercaderes del Buenos Aires virreinal: familia y comercio. Buenos Aires: La Flor.

Soulodre-La France, R. (2004). Región e imperio, el Tolima Grande y las reformas borbónicas en el siglo XVIII. Bogotá: Instituto Colombiano de Antropología e Historia.

ToquicA, C. (2008). A falta de oro: linaje, crédito y salvación. Una historia del real convento de Santa Clara de Santafé de Bogotá, siglos XVII y XVIII. Bogotá: Ministerio de Cultura.

Torres, J. (2011). Redes comerciales en el Nuevo Reino de Granada. El caso de los comerciantes mayoristas de Santafé de Bogotá, 1750-1810 (Tesis de pregrado). Universidad Nacional de Colombia, Bogotá.

Torres, J. (2012). Precios, oferta monetaria y crecimiento económico en Nueva Granada durante la segunda mitad del siglo XVIII. Ponencia presentada en el Encuentro Colombiano de Historia Económica, Bogotá.

Twinam, A. (1985). Mineros, comerciantes y labradores: las raíces del espíritu empresarial en Antioquia. 1763-1810. Medellín: Fundación Antioqueña para los Estudios Sociales.

VAlle, G. DEL (2012). Finanzas piadosas y redes de negocios. Los mercaderes de la Ciudad de México ante la crisis de Nueva España, 1804-1808. México: Instituto de Investigaciones Dr. José María Luis Mora.

Wobeser, G. (1998). El crédito de las instituciones eclesiásticas de la ciudad de México en el siglo XVIII. En M. P. Martínez y G. DEL VAlle (comps.). El crédito en Nueva España (pp. 176-202). México: Instituto de Investigaciones Dr. José María Luis Mora/El Colegio de Michoacán. 